\title{
The impact of various drying kinetics models on the prediction of sample temperature-time and moisture content-time profiles during moisture removal from stratum corneum
}

\author{
S. Kar ${ }^{a}$, X.D. Chen ${ }^{a, b, *}$, B.P. Adhikaric, S.X.Q. Lin ${ }^{a}$ \\ a Biotechnology and Food Engineering Group, Department of Chemical Engineering, Monash University, \\ Clayton Campus, Victoria 3800, Australia \\ $\mathrm{b}$ Department of Chemical Engineering, The University of Auckland, Private Bag 92019, Auckland City, New Zealand \\ c School of Science and Engineering, University of Ballarat, Victoria 3353, Australia
}

\section{Introduction}

It has been demonstrated in the past that hydration of stratum corneum has an effect on the permeability of hydrophilic permeants through skin in transdermal drug delivery applications (Scheuplein, 1965; Michaels et al., 1975; Blank et al., 1984; Potts and Francoeur, 1991; Liron et al., 1994). It is therefore essential to have proper mathematical models that can accurately predict the moisture content at any position within the stratum corneum and skin as a whole. Such models would become the stepping stone to the development of more user-friendly skin multi-compartment physiologically based pharmacokinetic (PBPK) models. These models can then be used to assess transdermal permeability of various drugs and toxins.

Past studies conducted in this area mostly relied on studying the process of moisture absorption (Stockdale, 1978; Blank et al., 1984; Potts and Francoeur, 1991). These studies were mostly experimental. The primary purpose of these studies was to evaluate the moisture diffusivity. The common feature in all these investigations was that they were all carried out at steady state. The time scale of such a process can be very large (up to several days) (Blank et al., 1984). Therefore, such results are not of much significance especially for pharmacokinetic studies of hydrophilic drugs and transdermal toxicological assessment studies. Liron et al. (1994) recognised this problem and carried out unsteady

\footnotetext{
* Corresponding author at: Biotechnology and Food Engineering Group, Department of Chemical Engineering, Monash University, Clayton Campus, Victoria 3800, Australia. Tel.: +61 3 99059344; fax: +61 399055686.

E-mail address: dong.chen@eng.monash.edu.au (X.D. Chen).

Received 1 May 2008; Received in revised form 24 October 2008; Accepted 30 October 2008
} 


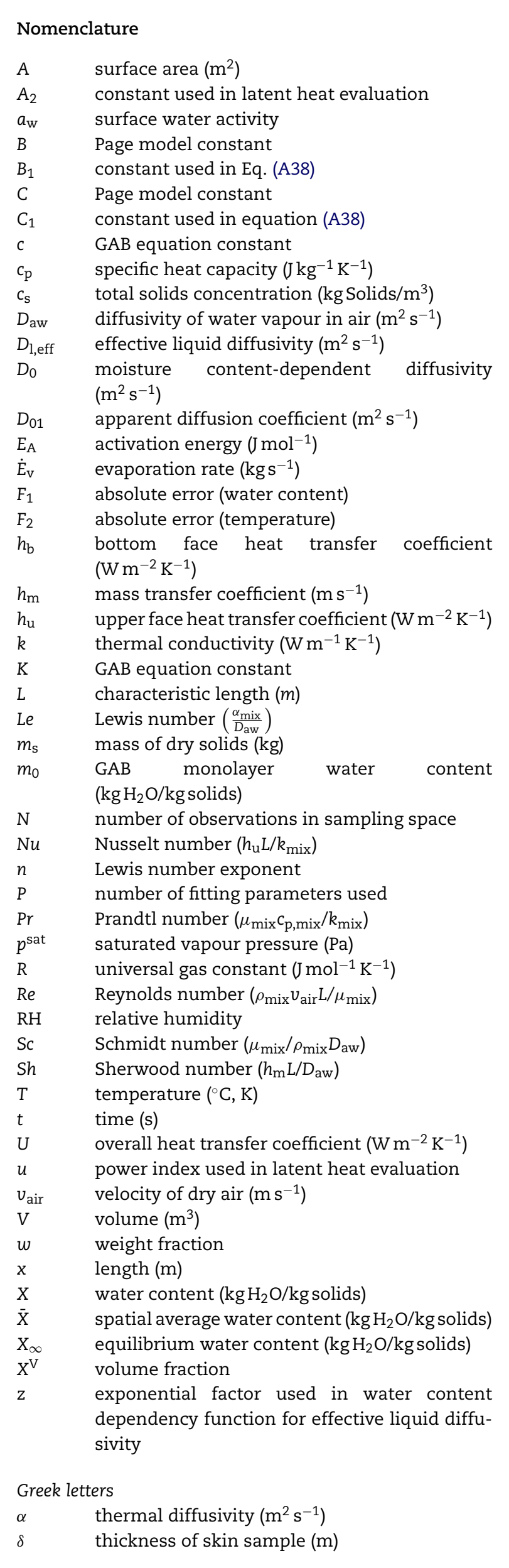

\begin{tabular}{|ll|}
\hline & \\
$\delta_{\text {dry }}$ & thickness of bone dry skin sample $(\mathrm{m})$ \\
$\varepsilon$ & porosity of skin sample \\
$\lambda_{1}$ & latent heat of vaporization $\left(\mathrm{Jg}^{-1}\right)$ \\
$\mu$ & viscosity $(\mathrm{Pa} \mathrm{s})$ \\
$\rho$ & density $\left(\mathrm{kg} \mathrm{m}^{-3}\right)$ \\
& \\
Subscripts \\
air & air \\
al & aluminium \\
cb & cardboard \\
exp & experimental \\
$\mathrm{f}$ & final condition \\
fat & fat \\
fibre & fibre \\
$i$ & ith component \\
mix & air water vapour mixture \\
paper & paper \\
plastic & plastic \\
protein & protein \\
s & interfacial condition \\
sample & skin/paper sample \\
skin & skin \\
solids & dry solids \\
v & vapour \\
w & water \\
water & water \\
$\infty$ & dry gas phase \\
0 & initial condition \\
\hline
\end{tabular}

state vapour sorption/desorption studies on porcine skin samples. Based on the mass gained/lost by the samples, the effective liquid diffusivity of moisture was estimated using Crank's analytical solution to diffusion equation (Crank, 1976). In all these studies the effective moisture diffusivity was considered to be a function of the skin moisture content.

The above attempts made for studying moisture transport across skin/stratum corneum had neglected the influence of temperature (ambient and skin sample) on moisture diffusivity. However, as will be shown later, temperature does play an important role, especially when predicting moisture content at any spatial location within the skin sample. This issue was later addressed by Kasting et al. (2003) when they attempted to correlate effective moisture diffusivity as a function of moisture content and temperature. The temperature dependency function was represented in the form of an Arrhenius relationship. The moisture content dependency on the other hand was dependent on the local water activity within the skin sample at any spatial location and certain micro-structural parameters such as pore radius within the skin sample and radius of water molecule.

While the approach of Kasting et al. (2003) did take into account the effect of temperature on effective moisture diffusivity, it did encounter problems, especially when the skin samples are completely saturated (occluded) with moisture (at saturation, $a_{\mathrm{w}}=\mathrm{RH}=1$ ). In such cases the diffusive flux would be completely absent. Kasting et al. (2003) did not encounter this problem as none of their case studies involved the use of saturated stratum corneum samples.

In the present study, the effect of both skin temperature and skin moisture content on moisture transport across 
porcine skin has been taken into account. In order to do so low temperature convective drying experiments of the skin samples were conducted. The reason for opting with drying experiments was the relative ease with which the temperature of the skin sample could be monitored during the dehydration process. This would have been difficult with the complex experimental setup used in the earlier studies (Stockdale, 1978; Blank et al., 1984; Potts and Francoeur, 1991). Furthermore, the time scale of these experiments is reasonably shorter (1-2h), which allows looking into the transient nature of moisture transport across skin samples.

In a study conducted by Gay et al. (1994), it was observed that a phase transition occurred for a subset of lipids in the stratum corneum. The phase transition temperature decreased from a value of $43^{\circ} \mathrm{C}$ at dehydrated state to $35^{\circ} \mathrm{C}$ at fully hydrated state.

Based on the information above, it was decided that the excised skin samples be cut in the form of thin sheets $(11.3 \mathrm{~mm} \times 11.3 \mathrm{~mm})$ and then pre-treated by soaking in water for $1 \mathrm{~h}$ at $25^{\circ} \mathrm{C}, 35^{\circ} \mathrm{C}$ and $45^{\circ} \mathrm{C}$, respectively. Subsequently these pre-treated skin samples were mounted on the sample plate and then dried at $25^{\circ} \mathrm{C}, 30^{\circ} \mathrm{C}$ and $37^{\circ} \mathrm{C}$ as described in the drying instrument section. The skin drying conducted at 'body temperature' of $37^{\circ} \mathrm{C}$ is given precedence here as the work has implications to the transdermal drug delivery project that is being undertaken by the same authors.

It is well known that drying is a coupled heat and mass transport process. The drying curves that were generated experimentally were initially fitted against the Page model (Page, 1949), using an optimisation algorithm (Lagarias et al., 1988). The Page model, known to be one of the best empirical model to fit thin layer drying data, produced reasonably good fits (relative to the liquid diffusion models) with a total of only two parameters. The aim of using an empirical model such as Page model was to make sure that the rate of drying can be calculated accurately in the first place.

The drying rate also forms a part of the energy equation, the solution of which predicts the temperature of the skin sample. It is envisaged that the drying rate predicted using Page model when introduced into the energy equation would render a temperature profile different to that obtained by solving simultaneously the liquid diffusion equation and the energy ordinary differential equation. This would thus allow the establishment or validation of an accurate model for energy balance. In other words, this would help us in separately examining the accuracy of the governing equation for the energy balance under the influence of two distinct drying kinetics models and indicate whether the accuracy of the drying kinetics models has a bearing on the sample temperature profile during drying.

The second model (liquid diffusion model) considers drying as an effective transport of liquid water through a porous hygroscopic medium (porcine skin in this case) (Schoeber, 1976; Stanish et al., 1986; Coumans, 1987; Pezzutti and Crapiste, 1997; Simal et al., 1998; Adhikari et al., 2002). The effective transport of liquid water lumps together the transport phenomena such as molecular diffusion, Darcian flow due to gas pressure or Darcian flow due to both gas and capillary pressure according to Datta (2007). While the process of molecular diffusion through the medium can be modelled mathematically using the well-known Fickian diffusion equation, modelling the Darcian flow pattern requires a priori knowledge of medium micro-structural properties such as relative permeability and tortuosity (Datta, 2007). In order to circumvent this problem, as numerous researchers have done, the combined effect of these flows might be mathematically represented in the single Fickian form with an effective liquid diffusivity (Datta, 2007). Hence the model to represent the movement of moisture here was taken in the form of a simple one-dimensional Fickian diffusion equation for infinite slab geometry.

Since Fickian diffusion equation is in the form of a parabolic partial differential equation, it needs an initial condition and two boundary conditions to be solved. The boundary condition at the skin sample surface undergoing evaporation consists of a convective term, which also forms a part of the energy equation. Therefore, the surface moisture content predicted using the liquid diffusion model should have an effect on the temperature prediction.

The temperature profile predicted by the solution of this energy equation coupled with the Fickian liquid diffusion model should then show whether the diffusion model is 'good enough or not'. It is therefore possible for the authors to conclude a few important points on the limitation of such a model approach. Furthermore, the current paper also demonstrates the mutual sensitivity between skin moisture content and temperature prediction.

\section{Experimental procedure}

\subsection{Skin sample preparation}

Pig ears were obtained from a local meat work (Diamond Valley Pork, Laverton, Victoria, Australia) within 2-3h after sacrifice. Subsequently, they were stored in sealed plastic bags in a laboratory freezer (TPR-900, Thermoline Scientific, NSW, Australia). These tissue samples were used within 2 days from the time they were procured from the meatworks. In order to remove the skin from the ear tissue, the samples were first warmed up by being kept in an atmosphere at $30^{\circ} \mathrm{C}$ for $3 \mathrm{~h}$. Thereafter the epidermis of fresh pig ears were separated from the underlying dermis by immersing the pig ears in distilled water at $60^{\circ} \mathrm{C}$ for a minute after which the skin could easily be peeled off using forceps. Similar procedures for removing skin from animal tissues were previously adopted by Blank et al. (1984) and Pieper et al. (2003). The thickness of the skin samples were in the range from 70 to $200 \mu \mathrm{m}$. This would encompass the epidermal layer as well (Michaels et al., 1975). However, since the moisture transport barrier is provided by the stratum corneum (Michaels et al., 1975), the skin tissues used in the present study are a reflection of moisture transport across stratum corneum itself (Liron et al., 1994).

\subsection{Drying instruments}

Fig. 1 shows the schematics of the drying instrument employed in this study. The excised skin samples were mounted in a specially made sample slot. The sample slot, where the skin was spread on, was made by stacking/gluing of two thin plastic sheets (each of $0.28 \mathrm{~mm}$ thickness), which is glued onto a cardboard sheet $(0.67 \mathrm{~mm}$ thickness), which then is glued onto a plate/stand made of aluminium $(0.98 \mathrm{~mm}$ thickness). The sample slot (or dent) was a square slot of $11.3 \mathrm{~mm} \times 11.3 \mathrm{~mm}$ which was cut in the top plastic sheet (thus having a depth of $0.28 \mathrm{~mm}$ ). The bottom plastic sheet was left intact. The skin sample was placed in the slot with tiny amount of edges ( $0.1 \mathrm{~mm}$ approximately) being "stuck" in 


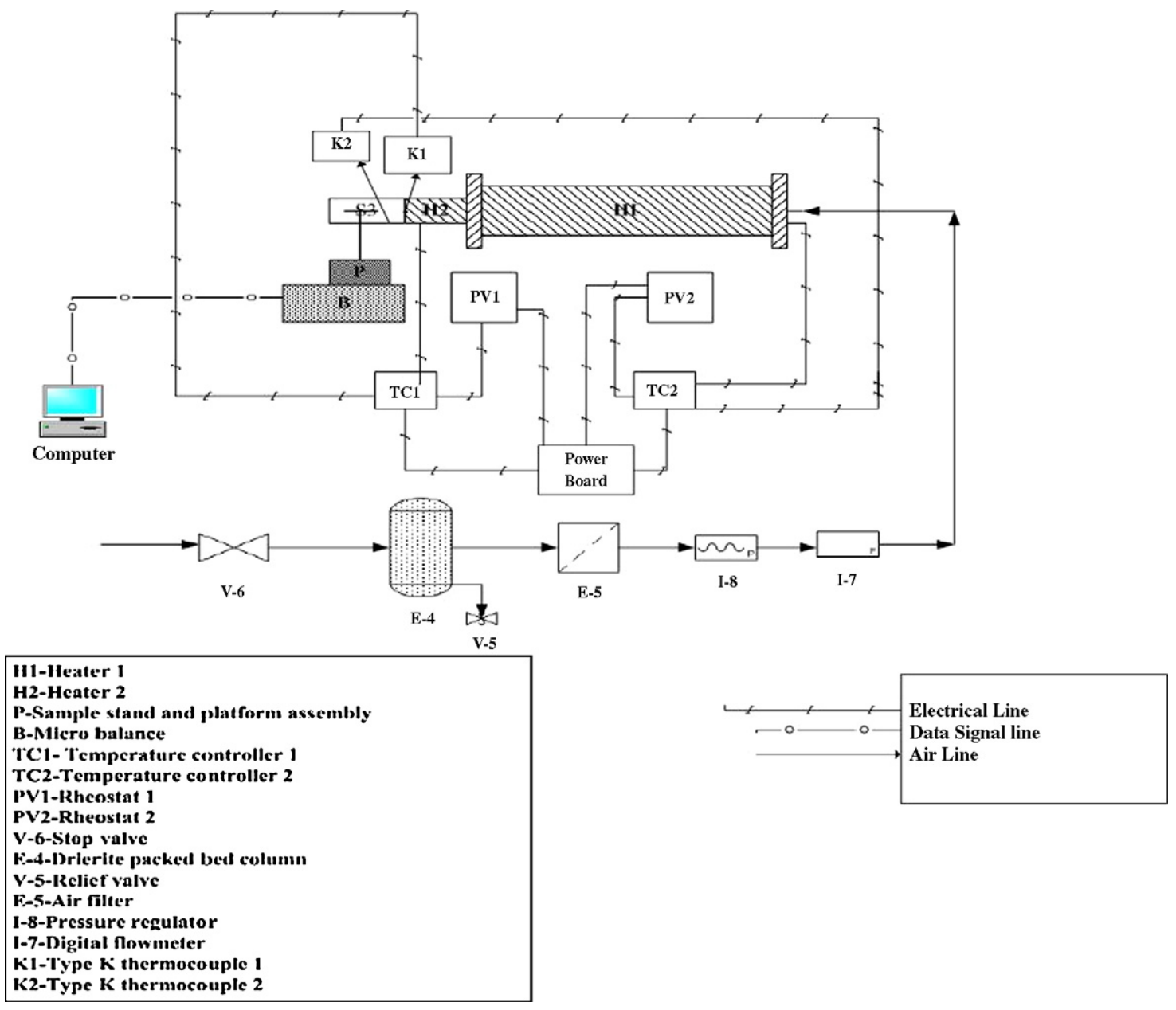

Fig. 1 - Schematic of the experimental setup.

between the two sheets. This ensured that the skin samples could not move or warp while drying is in progress. Fig. 2(a) shows the schematic of the sample plate/stand. This whole assembly was then mounted on to an electronic micro-balance (B) (Sartorius CP225D, Germany) with the base sitting on top of the balance pan (Fig. 2(b)). The balance was connected through a serial cable to a computer for data logging. The sampling interval was set at $10 \mathrm{~s}$ while the time scale of drying operation was in the order of 1.5-2 h.

In order to dry the skin sample, as shown in Fig. 2(a), an arrangement was made for the dry air stream to come in contact with the sample. A closer look at Fig. 1 indicates that the incoming air stream was dehumidified by passing it through a packed column (E-4) of anhydrous $\mathrm{CaSO}_{4}$ (drierite). The outlet air stream from the packed column was then passed through a cylindrical conduit (inner diameter $=35 \mathrm{~mm}$, length $=300 \mathrm{~mm}$ ) made of aluminium sheet (about $1 \mathrm{~mm}$ thickness) via an air filter (E-5) and a flow control meter (I-7). The dryness of the air at the drier section was verified using a relative humidity $(\mathrm{RH})$ probe (TRH-100, Pace Scientific, USA). Table 1 shows the variation of $\mathrm{RH}$ of dry air at different drying temperatures.

\section{Table 1 - Relative humidity of dry air at different} temperature.

\begin{tabular}{lc}
$\mathrm{T}_{\infty}\left({ }^{\circ} \mathrm{C}\right)$ & Relative humidity $(\%)$ \\
\hline 25 & 5.43 \\
35 & 3.79 \\
37 & 2.43 \\
\hline
\end{tabular}

(a) Air flow
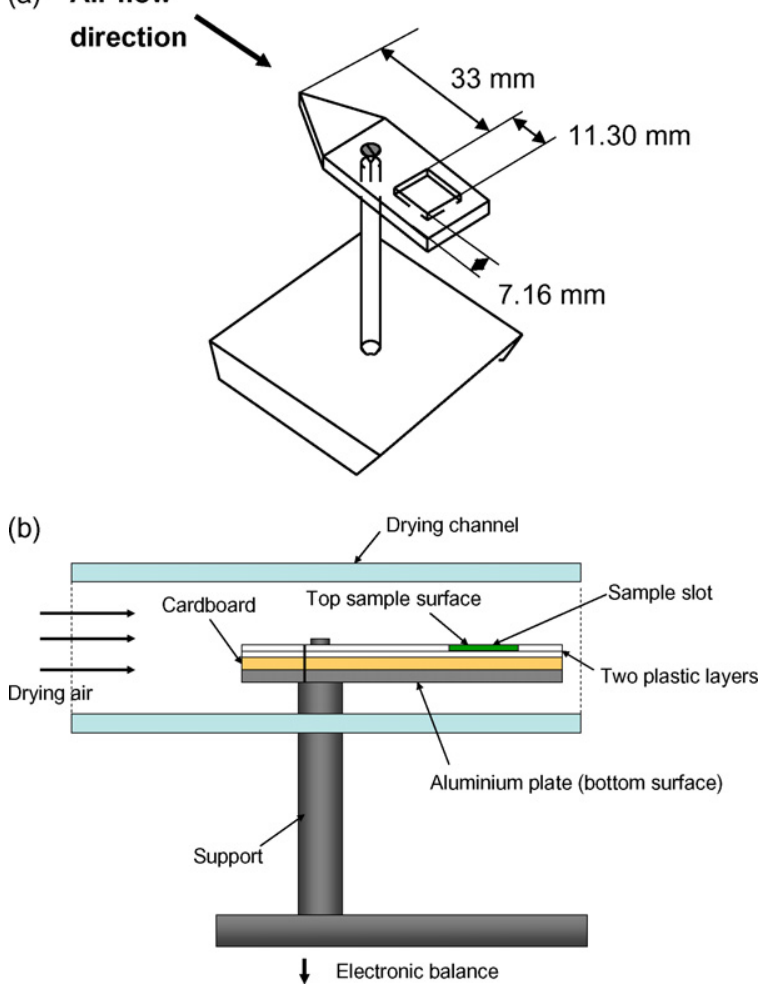

Fig. 2 - (a) Overview of the sample plate/stand assembly (not to scale). (b) Details of the layering structure for sample support (not to scale). 
The external surface of the aluminium conduit was wounded by nichrome wires to heat up the incoming air stream to the desired temperature. The voltage supply to the nichrome wire is regulated by a temperature controller (TC2). The cylindrical conduit described above was mounted concentrically inside a larger cylindrical conduit (inner diameter $=65 \mathrm{~mm}$ ). The annular space was packed with glass fibre to minimise heat loss. The entire assembly of the heater and concentric tubes is represented in Fig. 1 as $\mathrm{H} 1$.

Continuing with Fig. 1, one can see that the outlet from the cylindrical conduit was sealed except for a small rectangular slot $(30 \mathrm{~mm} \times 30 \mathrm{~mm}$ ). A rectangular channel was joined to this slot by flanges. The length of this channel was about $150 \mathrm{~mm}$ and was divided into two distinct sections. The first section was about $40 \mathrm{~mm}$ in length and was wounded by nichrome wire (H2). The voltage supply for this heater was regulated by another temperature controller (TC1). The peak voltage value set for this heater was much lower than the cylindrical conduit. This section of the rectangular channel was made of aluminium and insulated by glass fibre as well. The second section of the rectangular channel (S3) was partially made of glass (three faces except the lower) and aluminium (lower face). On the lower face, a narrow slot ( $3 \mathrm{~cm}$ wide) was cut along the entire length of the section. The purpose of this slot was to get the air inlet of the second rectangular segment as close as possible to the sample plate without contacting its support (the vertical stand). In addition to that, in the insulated section of the rectangular channel, a series of fine wired meshes have been placed to reduce the effect of turbulence in accordance with previous studies in the area of thin film drying performed by Räderer (2000). The peak voltages to the temperature controllers were supplied through two rheostats (PV1 and PV2).

As mentioned earlier, the power supply to both the heaters was regulated by two separate PID temperature controllers. The input signal to these temperature controllers was obtained from two Type $\mathrm{K}$ thermocouples (K1 and $\mathrm{K} 2$ ). The first thermocouple was placed on the mesh at the inlet of the second section of the rectangular channel. The second was placed on the lower face of the second section of the rectangular channel close to its inlet. The temperature controller adjusted the voltage supply to the heaters and maintained the temperature readings from both the thermocouple to a range of $\pm 0.2^{\circ} \mathrm{C}$ from the desired set point. The weight loss measurements for duplicate runs have been established to be within $\pm 5 \%$.

Based on the description of the experimental rig, especially the sample plate (Fig. 2(b)), it is clearly evident that the dry air coming in contact with the plate would streamline itself between the upper surface and the lower surface of the plate. While the upper surface of the plate is flat, the bottom surface is connected to the stand. Consequently, the heat transfer coefficient, at the upper face $\left(h_{\mathrm{u}}\right)$ is expected to be different from that at the bottom face $\left(h_{\mathrm{b}}\right)$ (aluminium metal surface faced down). The mass transfer coefficient $\left(h_{\mathrm{m}}\right)\left(\mathrm{ms}^{-1}\right)$ only needs to be computed for the upper surface as no mass transfer occurs from the bottom surface of the plate. The procedure for calculating the above parameters will be highlighted in the upcoming sections.

\subsection{Measurement of mass transfer coefficient $\left(h_{m}\right)$}

This is one of the major parameters that had to be estimated prior to commencement of the thin layer drying experiments and later modelling work. While it can be pointed out that use of conventional convective mass transfer correlations for flow along a flat plate might suffice but it was decided to verify the mass transfer coefficient experimentally.

In order to perform this experiment, thin sheets of paper were cut to the size $(11.3 \mathrm{~mm} \times 11.3 \mathrm{~mm})$ and soaked in water at room temperature $\left(20^{\circ} \mathrm{C}\right)$ for about $1 \mathrm{~h}$. The use of paper was to ensure the sample was consistent unlike a thin natural biomaterial such as skin. These water-saturated sheets were then placed on the sample plate similar to that for skin and let to dry under the influence of the dehumidified air stream. The temperature of the air stream was set to the desired temperature $\left(25^{\circ} \mathrm{C}, 30^{\circ} \mathrm{C}\right.$ and $37^{\circ} \mathrm{C}$, respectively) and the weight loss recorded from the balance. For each of the temperatures mentioned above, three separate runs were carried out. The average velocity of the air stream, calculated on the basis of the volumetric flow rate set by the flow meter and the flow area $(30 \mathrm{~mm} \times 30 \mathrm{~mm})$, assuming incompressible flow, was set to $1.0 \pm 0.1 \mathrm{~m} \mathrm{~s}^{-1}$ for all the experimental runs, including those involving drying of the skin samples. Following the weight loss experiments, the sample temperature during drying was measured in parallel runs maintaining the same drying conditions. A $0.2 \mathrm{~mm}$ diameter Type $\mathrm{K}$ thermocouple was placed against the paper sample.

The weight loss experiments showed that the water content (on dry basis) of the moist paper sample for all the experiments followed a linear trend for the drying period indicating the presence of a constant drying rate period (Schoeber, 1976; Treybal, 1980). Furthermore, no visible changes in the surface area were noted during drying of the paper samples. The sample (paper) temperature measured at this constant rate period did not seem to change a lot and for all cases reached a constant value immediately after the onset of the drying experiments $(<10 \mathrm{~s})$. This temperature is said to be the saturation temperature (Ashworth and Keey, 1972).

For the above-mentioned conditions, the following mathematical expression relating drying rate to the water vapour flux can be used to estimate the mass transfer coefficient:

$\frac{-m_{\mathrm{s}}}{\mathrm{A}} \frac{\mathrm{d} \overline{\mathrm{X}}}{\mathrm{dt}}=h_{\mathrm{m}}\left(\rho_{\mathrm{v}, \mathrm{s}}-\rho_{\mathrm{v}, \infty}\right)$

where $m_{\mathrm{s}}$ is the mass of bone dry solids $(\mathrm{kg}), \mathrm{A}$ is the area of the paper sample undergoing drying (top surface) $\left(\mathrm{m}^{2}\right), \overline{\mathrm{X}}$ is the spatial average moisture content of the sample on dry basis ( $\mathrm{kg} \mathrm{H}_{2} \mathrm{O} / \mathrm{kg}$ solids), $\rho_{\mathrm{v}, \mathrm{s}}$ is the interfacial vapour concentration $\left(\mathrm{kg} \mathrm{m}^{-3}\right)$ and $\rho_{\mathrm{v}, \infty}$ is the vapour concentration in the dehumidified air stream $\left(\mathrm{kg} \mathrm{m}^{-3}\right)$. Since $\rho_{\mathrm{v}, \mathrm{s}}$ can be considered to be the saturated value, the interfacial vapour concentration $\left(\rho_{\mathrm{v}, \mathrm{s}}\right)$ could be calculated from the sample temperature data using Antoine's equation and subsequently using the ideal gas law (Yaws, 1999).

The vapour concentration of the dehumidified air stream was monitored using the relative humidity sensor. The bone dry weight of the paper samples were obtained by drying the paper at $150^{\circ} \mathrm{C}$ in the oven for $2 \mathrm{~h}$. Fig. 3 shows the variation of mass transfer coefficient (experimental and predicted) with respect to the drying temperature (Table 2 shows these values).

The predicted values of mass transfer coefficient were calculated using the following convective mass transfer correlation for flow along a flat plate (Incropera and De Witt, 2000):

$\bar{S} h=0.664 R e^{1 / 2} S c^{1 / 3}$ 
Table 2 - Experimental and predicted mass transfer coefficient.

\begin{tabular}{cccc}
$T_{\infty}\left({ }^{\circ} \mathrm{C}\right)$ & $\begin{array}{c}h_{\mathrm{m}}(\text { experimental) } \\
\left(\mathrm{m} \mathrm{s}^{-1}\right)\end{array}$ & $\begin{array}{c}h_{\mathrm{m}} \text { (predicted) } \\
\left(\mathrm{m} \mathrm{s}^{-1}\right)\end{array}$ & $\begin{array}{c}\text { Standard deviation } \\
\text { (experimental) }\end{array}$ \\
\hline 25 & 0.028 & 0.034 & 0.001414 \\
35 & 0.029 & 0.034 & 0.000385 \\
45 & 0.040 & 0.035 & 0.001283 \\
\hline
\end{tabular}

where $\bar{S}$ h denotes the average value of Sherwood number over the entire length of the sample plate. Re and Sc denote the Reynolds number and Schmidt number, respectively. The above correlation is valid if the flow of air is laminar over the entire surface of the plate and the Schmidt number is greater than or equal to 0.6. The characteristic length used for the calculation of these dimensionless numbers is the length of the slot on which the skin sample is placed $(11.3 \mathrm{~mm})$. The predicted values are good benchmarks to check the validity of our mass transfer measurement. The thermo physical properties of an essentially air-vapour mixture used in calculation of the above dimensionless numbers namely density, specific heat capacity, diffusivity and viscosity was calculated using the method described in Kar and Chen (2004). All these thermo physical properties are evaluated at film temperature determined as $\left(T_{\infty}+T_{s}\right) / 2$. Based on the characteristic length chosen and the air velocity, both the pre-conditions required for equation (2) to be implemented were satisfied. The comparison between the predicted and the experimental values are also given in Table 2 . They agree to each other reasonably well though the variation against temperature is smaller for the predicted ones.

\subsection{Estimating the upper surface heat transfer} coefficient $\left(h_{u}\right)$ from the experimental mass transfer coefficient $\left(h_{m}\right)$

As suggested earlier, the upper surface heat transfer coefficient can be estimated from the experimentally determined mass transfer coefficient from the paper drying experiments using the boundary layer analogy (Incropera and De Witt, 2000):

$\frac{h_{\mathrm{u}}}{h_{\mathrm{m}}}=\rho_{\mathrm{mix}} c_{\mathrm{p}, \mathrm{mix}} L e^{1-n}$

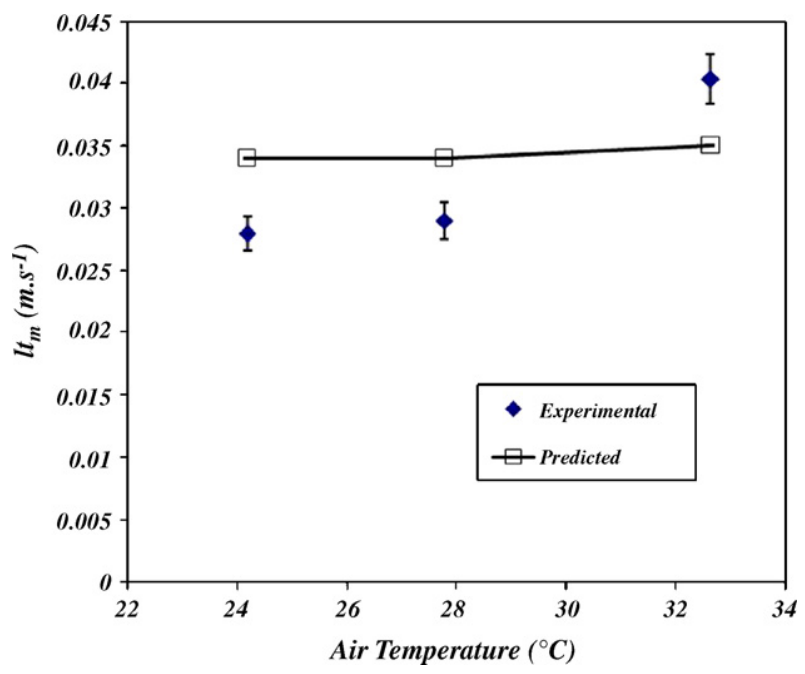

Fig. 3 - Variation of mass transfer coefficient with respect to drying temperature (mean \pm S.D.).

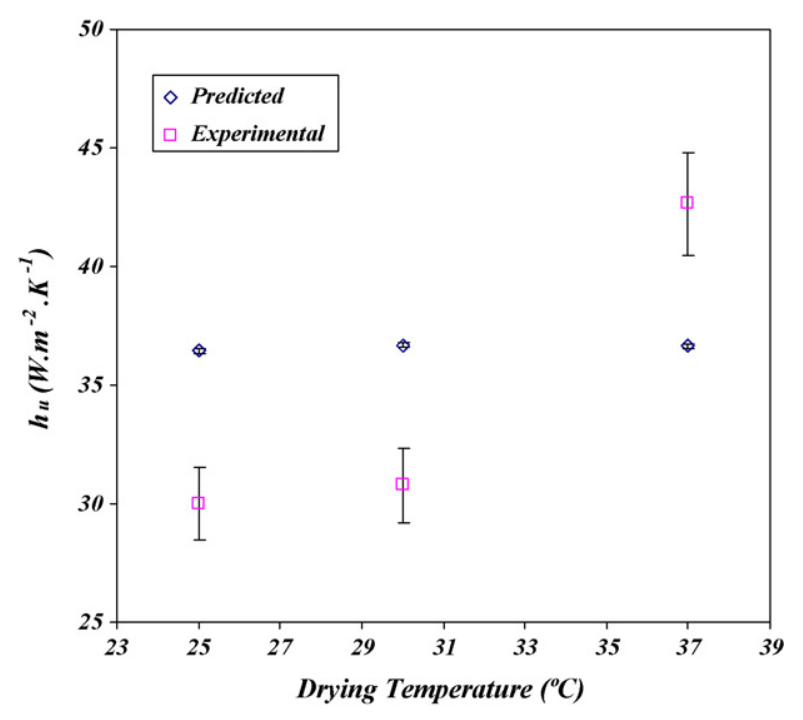

Fig. 4 - Variation of upper face heat transfer coefficient $\left(h_{\mathrm{u}}\right)$ with respect to drying temperature (mean \pm S.D.).

where $\rho_{\text {mix }}\left(\mathrm{kg} \mathrm{m}^{-3}\right)$ and $c_{\mathrm{p} \text {,mix }}\left(\mathrm{Jkg}^{-1} \mathrm{~K}^{-1}\right)$ represent the density and specific heat capacity of the air-water vapour mixture and are calculated at the film temperature (Incropera and De Witt, 2000). Le is the Lewis number and $n$ is a positive exponent, which is chosen as 1/3 (Incropera and De Witt, 2000).

Fig. 4 shows the values of the upper face heat transfer coefficient at different drying temperatures calculated using Eq. (3) and compares them with those calculated using the conventional convective mass transfer correlation for flow along a flat plate. This correlation is similar to that of Eq. (2) with Sherwood number (S̄h) being replaced by Nusselt number $(\overline{\mathrm{Nu}})$ and Schmidt number (Sc) being replaced by Prandtl number (Pr). Table 3 shows these values (experimental and predicted). The upper surface heat transfer coefficient $\left(h_{u}\right)$ calculated using this approach is then subsequently used for computation of the bottom surface heat transfer coefficient $\left(h_{b}\right)$ as will be demonstrated in the latter sections.

\subsection{Skin drying experiments}

The skin drying experiments were carried out at $25^{\circ} \mathrm{C}, 30^{\circ} \mathrm{C}$ and $37^{\circ} \mathrm{C}$ for different pre-treated skin samples, respectively, as mentioned earlier (refer Section 1). The procedure has been described in details in Section 2.2. The change in weight of the

Table 3 - Upper surface heat transfer coefficient from paper drying experiments.

\begin{tabular}{|c|c|c|}
\hline $\mathrm{T}_{\infty}\left({ }^{\circ} \mathrm{C}\right)$ & $\begin{array}{l}h_{\mathrm{u}}\left(\mathrm{W} \mathrm{m}^{-2} \mathrm{~K}^{-1}\right) \\
\text { (experimental) }\end{array}$ & $\begin{array}{c}h_{\mathrm{u}}\left(\mathrm{Wm}^{-2} \mathrm{~K}^{-1}\right) \\
\text { (predicted) }\end{array}$ \\
\hline 25 & 30 & 36.46 \\
\hline 30 & 30.78 & 36.47 \\
\hline 37 & 42.64 & 36.64 \\
\hline
\end{tabular}




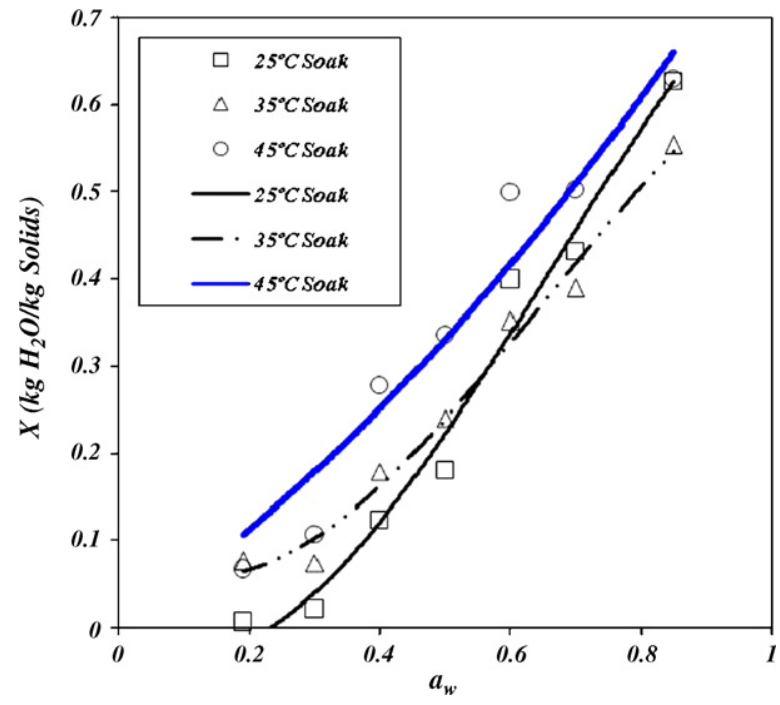

Fig. 5 - Sorption isotherm of porcine skin at $37^{\circ} \mathrm{C}$.

sample during drying was recorded at $10 \mathrm{~s}$ intervals. Thereafter an approximately identical skin sample from the same tissue was mounted on the sample plate and a Type $\mathrm{K}$ thermocouple of $0.2 \mathrm{~mm}$ diameter was gently slid into the skin sample sideways and dried under similar conditions to that of its corresponding weight loss experiments. The thermocouple was connected to a data logger (Picologger, Pico Scientific, UK) and the sample temperature was recorded at every $10 \mathrm{~s}$ intervals.

At the termination of the drying experiments, the skin samples were introduced into an oven at $100^{\circ} \mathrm{C}$ for 2 days to obtain its bone dry weight. Prior to and on termination of the skin drying experiments, the thickness of the skin samples were noted using a digital micrometer (All Lab Scientific, NSW, Australia). The thicknesses were also monitored after the bone dry weights were measured. No visible changes were observed in the area of the skin samples during or after drying. While drying of skin at $100^{\circ} \mathrm{C}$ could lead to denaturation of keratin present in the skin samples (Lin et al., 1996; Tanojo et al., 1997), it would not lead to evaporation of the lipids present in it (Golden et al., 1986). Furthermore, since measuring the bone dry weight of the skin samples is the given objective, it is well served using the above protocol.

\section{Modelling and analysis}

\subsection{Empirical fit of water content profile for skin samples}

As mentioned earlier, two models were used to correlate the drying kinetics. In the first model, the experimental drying curves were first fitted using Page model with the aid of the optimisation algorithm. The Page model is usually written as (Page, 1949):

$\frac{\bar{X}-\bar{X}_{\infty}}{\bar{X}_{0}-\bar{X}_{\infty}}=\exp \left(-B t^{C}\right)$

where $\bar{X}$ represents the spatial average water content of the skin sample at any time. $\bar{X}_{0}$ and $\bar{X}_{\infty}$ denotes the initial and equilibrium moisture content, respectively. The equilibrium moisture content is estimated from the moisture sorption isotherm developed during this study and explained in details elsewhere (Kar, 2008). Fig. 5 shows the sorption isotherm for the different pre-treated skin samples at $37^{\circ} \mathrm{C}$ where $\mathrm{RH}$ represents the ambient relative humidity under which the skin sample is stored/dried. It is also referred to as water activity $\left(a_{\mathrm{w}}\right)$. B and C are fitting parameters. The choice of Page model was based on the abundant literature evidence to be the best empirical model for thin layer drying (Doymaz, 2005; Akpinar and Bicer, 2005; Vijayraj et al., 2007; Sutar and Prasad, 2007).

\subsection{Estimation of the bottom surface heat transfer coefficient $\left(h_{b}\right)$ using optimisation procedure}

The bottom surface heat transfer coefficient $\left(h_{b}\right)$ can be determined by optimising the solution of the energy balance equation for the skin sample undergoing drying with respect to the experimental temperature trends. Mathematically, the energy equation is represented as

$$
\begin{aligned}
\rho_{\text {skin }} c_{\mathrm{p}, \operatorname{skin}} \mathrm{V}_{\text {skin }} \frac{\mathrm{dT}}{\mathrm{dt}}= & h_{\mathrm{u}} \mathrm{A}\left(\mathrm{T}_{\infty}-\mathrm{T}\right)-h_{\mathrm{m}} \mathrm{A}\left(\rho_{\mathrm{v}, \mathrm{s}}-\rho_{\mathrm{v}, \infty}\right) \lambda_{l} \\
& +\mathrm{UA}\left(\mathrm{T}_{\infty}-\mathrm{T}\right)
\end{aligned}
$$

$\frac{1}{\mathrm{U}}=\frac{1}{h_{\mathrm{b}}}+\frac{\delta_{\mathrm{cb}}}{k_{\mathrm{cb}}}+\frac{\delta_{\mathrm{al}}}{k_{\mathrm{al}}}+\frac{\delta_{\text {plastic }}}{k_{\text {plastic }}}$

where $\rho_{\text {skin }}, c_{\mathrm{p} \text {,skin }}$ and $\mathrm{V}_{\text {skin }}\left(\mathrm{m}^{3}\right)$ denotes the density, specific heat capacity and volume of the skin sample, respectively. All these parameters are a function of temperature and moisture content and can be estimated from the correlations developed by Choi and Okos (1986). Sample calculations of these properties will be discussed in the appendix (refer Appendix A.1) of this paper. $A$ is the surface area of the sample heated and dried $\left(\mathrm{m}^{2}\right)$.

The last term on the RHS of Eq. (5) represents the heating from bottom. $h_{\mathrm{m}}, h_{\mathrm{u}}$ and $h_{\mathrm{b}}$ denote the convective mass and upper and bottom surface convective heat transfer coefficient, respectively. While $h_{\mathrm{m}}$ is evaluated experimentally and $h_{\mathrm{u}}$ obtained from it using the boundary layer analogy (Incropera and De Witt, 2000) as described earlier (Section 2.4) from the paper drying experiments, the bottom surface heat transfer coefficient $h_{\mathrm{b}}$ is evaluated by fitting the solution of the energy equation to the experimental temperature profile. $\lambda_{1}$ is the latent heat of vaporization of water calculated at the skin temperature $\left(\mathrm{J} \mathrm{kg}^{-1}\right)$. The overall heat transfer coefficient $U$ $\left(\mathrm{W} \mathrm{m}^{-2} \mathrm{~K}^{-1}\right.$ ) for the lower face of the sample plate represents the thermal resistances in series due to the presence of aluminium plate, cardboard, plastic sheet and the bottom face heat transfer coefficient $\left(h_{b}\right)$, respectively. The values for their thicknesses along with the method of estimating their thermal conductivities are presented in the appendix (refer Appendix A.1). $T_{\infty}$ is the temperature of dry air.

Upon having a closer look at Eq. (5), the second term of the RHS represents the heat loss due to evaporation. This term can be re-written in terms of the Page model parameters for the specific case of concern by differentiating Eq. (4) with respect to time and substituting it in Eq. (1). Furthermore, since the RHS of Eq. (1) is the same as the second term of the RHS of Eq. (5), Eq. (5) can be re-written as

$\rho_{\text {skin }} c_{p, \text { skin }} V_{\text {skin }} \frac{d T}{d t}=h_{u} A\left(T_{\infty}-T\right)+\dot{E}_{v} \lambda_{1}+U A\left(T_{\infty}-T\right)$

and the vapour flux due to evaporation $\left(\mathrm{kg} \mathrm{s}^{-1}\right)$ is

$\dot{\mathrm{E}}_{v}=m_{\mathrm{s}} B C \mathrm{t}^{\mathrm{C}-1}\left(\overline{\mathrm{X}}_{0}-\overline{\mathrm{X}}_{\infty}\right) \mathrm{e}^{-\mathrm{Bt} \mathrm{t}^{\mathrm{C}}}$ 
The overall heat transfer coefficient $U$ is considered a constant since the variations of the thermal conductivities of these different layers do not vary significantly at all within the temperature range for which the drying experiments were carried out (refer to Appendix A.1). It is also expected that the bottom surface temperature is reasonably close to the air stream temperature thus making the film properties approximately constant in each drying run.

The solution of Eq. (7) gives the temperature-time profile of the skin sample during the drying process. The predicted profile generated by this equation is fitted against the experimental temperature profile using the optimisation algorithm. The purpose of this was to use the optimisation program to obtain the bottom surface heat transfer coefficient $\left(h_{\mathrm{b}}\right)$. This was the only variable which needed to be resolved. At $37^{\circ} \mathrm{C}$ drying air condition, the $h_{\mathrm{b}}$ values yielded by the optimisation procedure for the different experimental trials were in the range from 43.9 to $44.6 \mathrm{~W} \mathrm{~m}^{-2} \mathrm{~K}^{-1}$ (refer Table 6). Comparing with the heat transfer coefficient at the upper surface $\left(h_{u}\right)$ calculated at $37^{\circ} \mathrm{C}$ from the paper drying experiments $\left(42.6 \mathrm{~W} \mathrm{~m}^{-2} \mathrm{~K}^{-1}\right), h_{\mathrm{b}}$ is somewhat higher but not too much different from $h_{\mathrm{u}}$ as expected.

The purpose of using Page model parameters in the energy equation (Eq. (7)) to evaluate the bottom surface heat transfer coefficient $\left(h_{b}\right)$ is to isolate its effect on the temperature prediction of skin sample during drying when the energy equation is solved in conjunction with the liquid diffusion equation. This would then clearly indicate the accuracy of the drying kinetics models on the temperature prediction.

It may be argued that since the upper surface heat transfer coefficient $\left(h_{\mathrm{u}}\right)$ is obtained from paper drying experiments, the same may not be applicable for skin drying scenario. The justification behind using paper drying experiments to evaluate $h_{\mathrm{u}}$ and skin drying experiments to evaluate $h_{\mathrm{b}}$ has been shown in the appendix (refer to Appendix A.3).

\subsection{Justifying the uniform temperature assumption}

Eq. (7) can only be applied if the assumption of uniform temperature within the skin sample holds true. This is justified using the Biot number calculation. For example, at $37^{\circ} \mathrm{C}$ and relative humidity of $40 \%$, based on the isotherms shown in Fig. 5, the water content of stratum corneum soaked at $25^{\circ} \mathrm{C}$ was found to be $51 \%$ by weight. The composition of protein and fat were found to be 33 and $16 \mathrm{wt} \%$, respectively, based on the data provided by Michaels et al. (1975).

On the basis of the above chemical composition and temperature, the thermal conductivity of the components making up the skin sample can be estimated from the correlations developed by Choi and Okos (1986). Thereafter incorporation of the series and the parallel model for thermal conductivity developed by Krischer (Keey, 1972), and taking the average of the two, a realistic estimate of the thermal conductivity of the skin sample has been worked out, i.e. $0.23 \mathrm{~W} \mathrm{~m}^{-1} \mathrm{~K}^{-1}$.

In the experiments conducted for skin drying, the thickness of skin samples measured varied from 72 to $200 \mu \mathrm{m}$. The maximum value of thickness (i.e. $200 \mu \mathrm{m}$ ) is taken. The upper face heat transfer coefficient $\left(h_{\mathrm{u}}\right)$ estimated previously at $37^{\circ} \mathrm{C}$ from the paper drying experiments (Section 2.4) was found to have a value of $42.6 \mathrm{~W} \mathrm{~m}^{-2} \mathrm{~K}^{-1}$. Based on these parameters, the Biot number was calculated to be 0.035 . This value is below the critical limit (Chen and Peng, 2005) for the system of conduction and convection combined (Incropera and De Witt, 2000) and if the evaporative effect is taken into account (Chen and
Peng, 2005), this condition is even more appropriate for the assumption of uniform temperature. Therefore, in any case, the uniform temperature assumption is fairly reasonable. The mathematical form of the Biot number has been shown in the appendix (refer Appendix A.1).

\subsection{The temporal temperature and spatial average water content profiles predicted using the Fickian liquid diffusion approach-the sensitivity assessment for 'constant diffusivity' cases}

Here, the drying process is assumed to be an effective liquid diffusion process and can hence be mathematically represented as (Schoeber, 1976; Pakowski et al., 2006; Pakowski and Mujumdar, 2006):

$c_{s}(X, T) \frac{\partial X}{\partial t}=\frac{\partial}{\partial x}\left(D_{l, e f f} c_{s}(X, T) \frac{\partial X}{\partial x}\right)$

where $D_{1, \text { eff }}$ represents the effective liquid diffusivity and is considered as a constant in this case. $x$ is the co-ordinate into the thickness and $X$ the water content of the skin sample in dry basis. $c_{\mathrm{s}}$ represents the total solids concentration $\left(\mathrm{kg} \mathrm{m}^{-3}\right)$ and is a function of skin water content and temperature. It is calculated using the following relation (Adhikari et al., 2002; Kar, 2008):

$c_{\mathrm{s}}=\frac{1-\varepsilon}{\left(1 / \rho_{\mathrm{solids}}\right)+\left(\mathrm{X} / \rho_{\mathrm{w}}\right)}$

where $\rho_{\text {solids }}$ and $\rho_{\mathrm{w}}$ denotes the 'pure' densities of the bone dry solids (protein and fat) and water, respectively. $\varepsilon$ denotes the porosity of the skin sample. The method used for calculating $\rho_{\text {solids }}$ and estimation of the solid concentration $\left(c_{\mathbf{S}}\right)$ has been described in the appendix (refer Appendix A.1). The effect of sample shrinkage during drying has not been taken into account in the diffusion equation (Eq. (9)). The initial condition and the two boundary conditions are

Initial condition

$t=0, \quad 0 \leq x \leq \delta, \quad X=X_{0}$

Boundary condition 1

$x=0, \quad 0<t \leq t_{f}, \quad c_{s} D_{1, \text { eff }} \frac{\partial X}{\partial x}=0$

Boundary condition 2

$x=\delta, \quad 0<t \leq t_{\mathrm{f}}, \quad c_{\mathrm{s}} D_{1, \mathrm{eff}} \frac{\partial \mathrm{X}}{\partial \mathrm{x}}+h_{\mathrm{m}}\left(\rho_{\mathrm{v}, \mathrm{s}}-\rho_{\mathrm{v}, \infty}\right)=0$

where $\delta(m)$ and $t_{\mathrm{f}}(\mathrm{s})$ denotes the thickness of the skin sample and the time of termination of the drying experiment, respectively. The surface vapour concentration in Eq. (13) can be determined only if the water activity data at $37^{\circ} \mathrm{C}$ for skin at the different pre-treatment conditions are available. Fig. 5 shows the moisture sorption isotherm for porcine skin subjected to the different pre-treatment conditions. The isotherm data in Fig. 5 were then fitted with the threeparameter $G A B$ model using the curve fitting toolbox in MATLAB (Mathworks Inc., USA). The GAB model parameters $\left(m_{0}, c\right.$ and $\left.K\right)$ for the skin sample subjected to different pre-treatment conditions are shown in Table 4. In Table 4, the parameter $m_{0}$ represents the monolayer water content. 
Table 4 - GAB model constants for different pre-treated skin samples at $37^{\circ} \mathrm{C}$.

\begin{tabular}{lccc} 
Pre-treatment method & $m_{0}$ & $c$ & $K$ \\
\hline $25^{\circ} \mathrm{C}$ soak & 0.1815 & 3.3360 & 0.8776 \\
$35^{\circ} \mathrm{C}$ soak & 0.2494 & 2.2806 & 0.7597 \\
$45^{\circ} \mathrm{C}$ soak & 0.7121 & 1.6932 & 0.4857 \\
\hline
\end{tabular}

Whereas the parameters $\mathrm{c}$ and $\mathrm{K}$ may be related to the effect of temperature (Rahman, 2000).

This diffusion equation (Eq. (9)) has to be solved in conjunction with the energy equation, which is similar to Eq. (5) and all the parameters are the same as in Eq. (5). Hence they will not be re-written here. However, the second term on the RHS of Eq. (5) at every time-step is obtained from the second boundary condition of the liquid diffusion equation (Eq. (13)). Eq. (5) is an ordinary differential equation and needs an initial condition to be solved. This is as follows:

$t=0, \quad T=T_{\text {initial }}$

The solution of Eq. (9) predicts the temporal variation in moisture content of the skin sample and that of Eq. (5) predicts the temporal variation in the temperature of the skin sample. The time-moisture content profile predicted by the solution of the liquid diffusion equation varies at each spatially discrete interval. In order to obtain the spatial average water content, the following was performed at each time step:

$\bar{X}=\frac{\int_{0}^{\delta} X d x}{\int_{0}^{\delta} d x}$

While the spatial average water content profile generated by the solution of the diffusion equation will be optimised against the experimental moisture content trends, the temperature profile generated by the solution of Eq. (5) will not be optimised. The reason for opting against this optimisation has already been emphasized in the introduction section of this paper. As the optimisation algorithm has been implemented on a large scale in this paper, a short note pertaining to this has been mentioned in the appendix (refer Appendix A.2).

Eq. (9) was solved numerically using the method of lines using the function 'pdepe' in MATLAB (Mathworks Inc., USA, 2006). Initially the thickness of the skin sample was discretised into 21 mesh points for solving the partial differential equation. Thereafter the number mesh points were increased to 41 . However, no visible improvements were noted in the solution profile. Hence for all computations, it was decided to persist with a total of 21 mesh points itself. Fig. 6 shows the impact of spatial discretization intervals on the solution profile of the diffusion equation.

The impact on number of time steps has also been investigated. The entire experimental duration was divided into a discrete number of time-steps. In this case they were discretised on a 10, 5 and $1 \mathrm{~s}$ basis. Fig. 7 shows the impact of choosing the different methods of temporal discretization. It clearly shows that reducing the time-step to below $10 \mathrm{~s}$ does not seem to have an impact on the solution profile. It was therefore decided to persist with a $10 \mathrm{~s}$ time-step as it would generate solution profiles in accordance with the experimental sampling interval (also $10 \mathrm{~s}$ ) thereby facilitating the

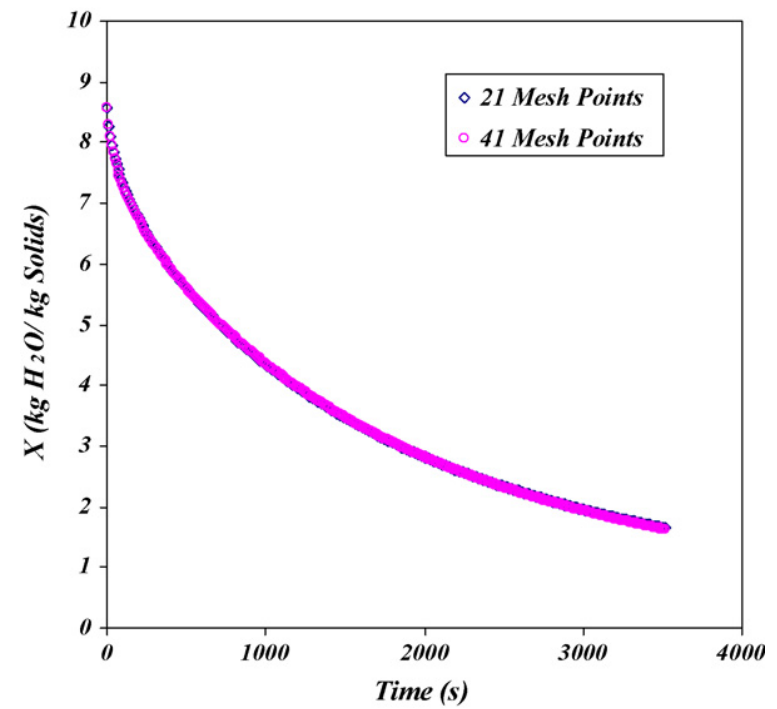

Fig. 6 - Effect of mesh points on solution profile.

optimisation procedure. Eq. (5) on the other hand has been solved using the MATLAB solver 'ode15s'. Further information regarding this solver can be found in MATLAB instruction manuals (Mathworks Inc., USA).

The pre-treated skin samples were dried at $37^{\circ} \mathrm{C}$. Fig. 8 shows the water loss profiles for the skin samples pre-treated at different conditions and Fig. 9 shows the temperature profile during drying for the same. The experimental moisture loss profiles demonstrated in Fig. 8 were first fitted using the Page model. While the Page model fitting was carried out for all the cases, for the sake of brevity, only two cases will be discussed here, which clearly addresses the objective of this paper. In Fig. 10, the experimental moisture loss trends for skin sample pre-soaked at $25^{\circ} \mathrm{C}$ and dried at $37^{\circ} \mathrm{C}$ are plotted along with their fitted profiles. Fig. 10 shows that the Page model produces reasonably good fits. This can further be argued from the statistical viewpoint. The sum of squared error (SSE) and root mean squared error (RMSE) values for the fits have been shown in Table 5. Mathematically, the SSE and RMSE values are computed at each time step using the following relations:

$\mathrm{SSE}=\frac{\sum_{i=1}^{N}\left(X_{t=i, \exp }-X_{t=i, \text { predicted }}\right)^{2}}{N-P}$

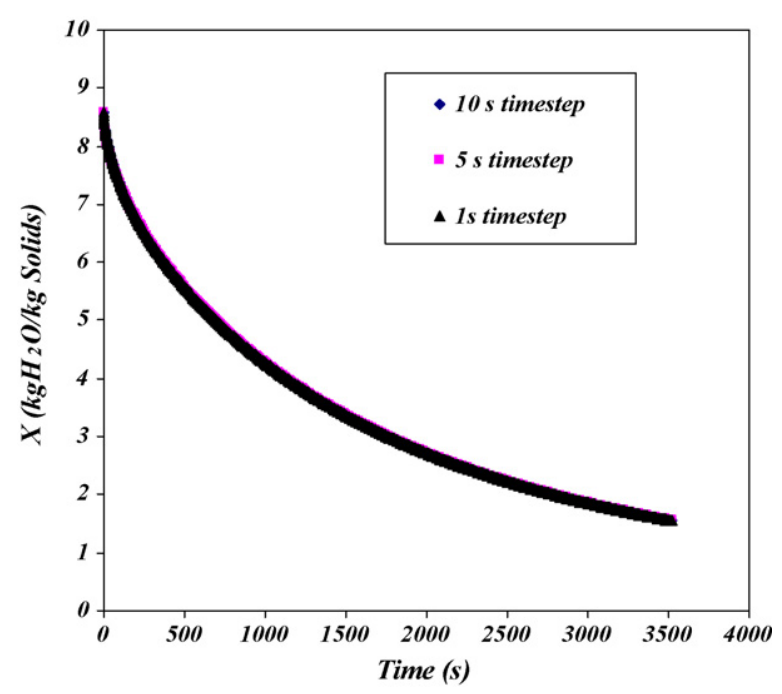

Fig. 7 - Effect of time step selection on solution profile. 


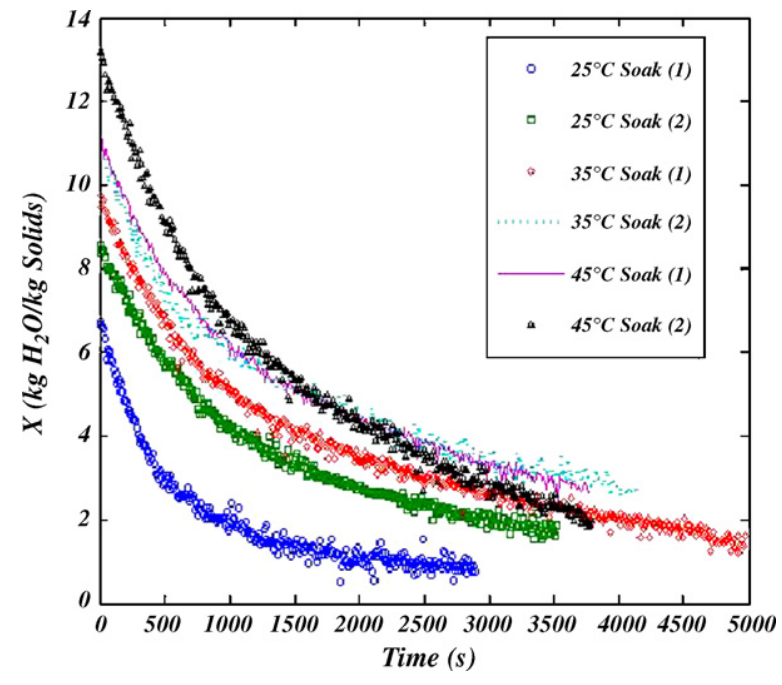

Fig. 8 - Moisture loss profiles for skin samples dried at $37^{\circ} \mathrm{C}$.

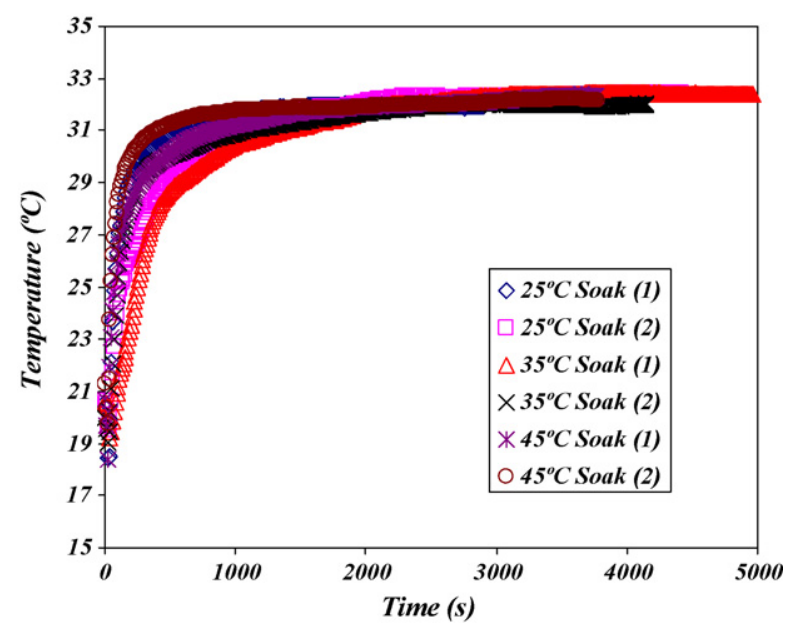

Fig. 9 - Temperature profiles of skin samples dried at $37^{\circ} \mathrm{C}$.

$\operatorname{RMSE}=\left[\frac{1}{N} \sum_{i=1}^{N}\left(X_{t=i, \exp }-X_{t=i, \text { predicted }}\right)^{2}\right]^{1 / 2}$

where $X_{t=i, \exp }$ denotes the moisture content of the skin sample determined experimentally at time $(t=i)$ and $X_{t=i \text {,predicted }}$ is the

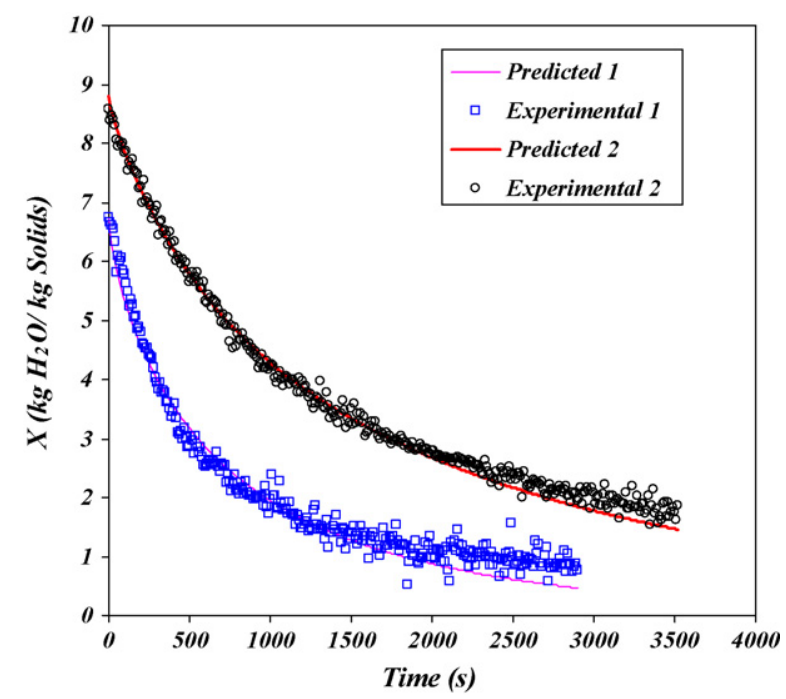

Fig. 10 - Predicted moisture loss profiles using Page model.
Table 5 - SSE and RMSE values associated with fitting

the moisture loss profiles. Diffusion model 1 (constant liquid diffusivity), diffusion model 2 (variable liquid diffusivity).

\begin{tabular}{llll} 
Trial No & \multicolumn{1}{c}{ Model } & SSE & RMSE \\
\hline 1 & Page model & 0.0230 & 0.1516 \\
1 & Diffusion model 1 & 0.0655 & 0.2560 \\
1 & Diffusion model 2 & 0.0280 & 0.1697 \\
2 & Page model & 0.0275 & 0.1657 \\
2 & Diffusion model 1 & 0.0450 & 0.2130 \\
2 & Diffusion model 2 & 0.0310 & 0.1780 \\
\hline
\end{tabular}

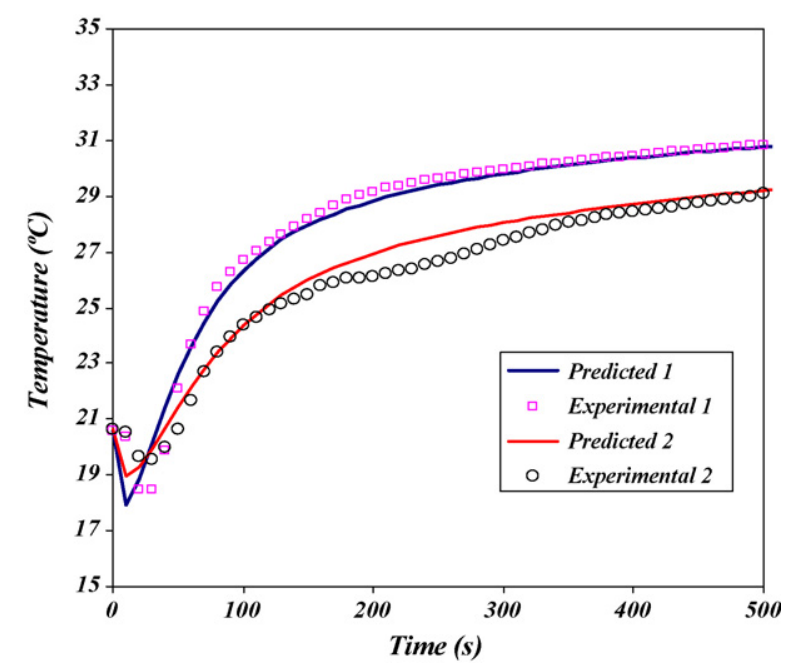

Fig. 11 - Predicted sample temperature profiles from energy equation using Page model parameters.

moisture content predicted using page model at time $(t=i)$. N and $P$ denote the number of observations and the number of fitting parameters used, respectively.

The Page model constants were then incorporated into the energy equation (Eq. (7)) and its solution was fitted against their respective experimental temperature trends. Fig. 11 shows the profiles. From Fig. 11 it is clearly visible that the predicted temperature profiles obtained from optimising the solution of Eq. (7) agrees quite well with the experimental temperature profiles. The optimisation of the solution generated by the energy equation provides the values of the bottom surface heat transfer coefficient $\left(h_{b}\right)$. The values of the bottom surface heat transfer coefficient $\left(h_{b}\right)$ obtained from the above procedure have been tabulated in Table 6 .

The bottom surface heat transfer coefficient obtained from the procedure above was subsequently used in the energy equation (Eq. (5)). The energy equation was then simultaneously solved with the liquid diffusion equation (Eq. (9)). The solution of the liquid diffusion equation was optimised against the experimental moisture content trends. Fig. 12 shows the fitted moisture content profiles along with the experimental ones. The goodness of the fits obtained was statistically quantified based on the SSE and RMSE values, which have been tabulated in Table 5. The observations from Table 5 clearly point out that the Page model produces better fits for the moisture loss profiles.

The solution of the energy equation coupled with the 'optimised' diffusion model predicts the temperature profile, which were also compared with the experimental temper- 
Table 6 - Bottom face heat transfer coefficient $\left(h_{b}\right)$ for different experimental runs.

\begin{tabular}{lccc} 
Pre-treatment & Drying temperature $\left({ }^{\circ} \mathrm{C}\right)$ & $h_{\mathrm{b}}\left(\mathrm{W} \mathrm{m}^{-2} \mathrm{~K}^{-1}\right)$ & $\mathrm{RMSE}$ \\
\hline $25^{\circ} \mathrm{C}$ soak & 37 & 46.16 & 0.1099 \\
$25^{\circ} \mathrm{C}$ soak & 37 & 47.14 & 0.2103 \\
$35^{\circ} \mathrm{C}$ soak & 37 & 48.15 & 0.2467 \\
$35^{\circ} \mathrm{C}$ soak & 37 & 48.13 & 0.4585 \\
$45^{\circ} \mathrm{C}$ soak & 37 & 46.02 & 0.4967 \\
$45^{\circ} \mathrm{C}$ soak & 37 & 45.96 & 0.2958 \\
\hline
\end{tabular}

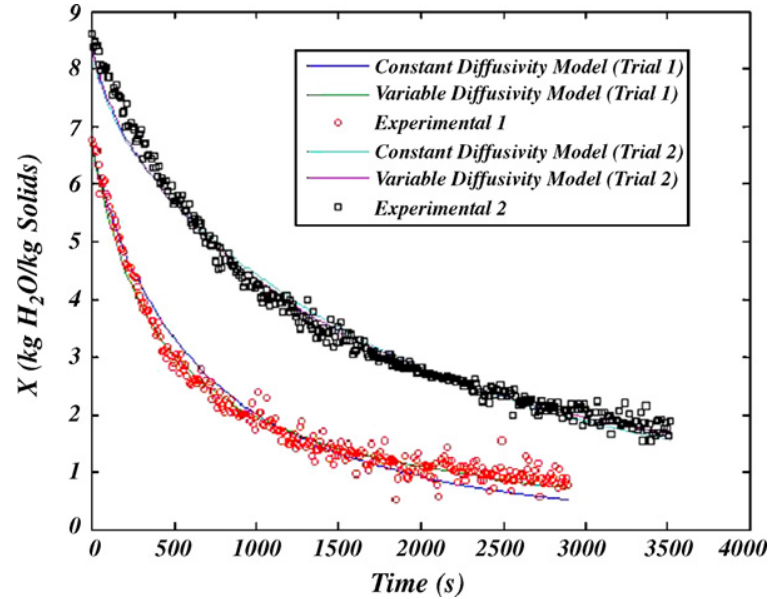

Fig. 12 - Predicted moisture loss profiles from solution of coupled liquid diffusion and energy equations.

ature trends. Fig. 13(a) and (b) shows the comparison. The cases shown in Figs. 12 and 13 were for the same situation as shown in Figs. 10 and 11. One can see in Fig. 12, the weight loss data were not as well predicted as those using the Page model. This has got ramifications in the temperature predictions as observed in Fig. 13(a), where the constant diffusivity model fails to accurately represent the initial temperature drop. This can be further corroborated from the SSE and RMSE data as shown in Table 5. The predictions shown in Fig. 13(b) are good as the constant diffusivity model generates good fits with respect to the experimental moisture content trend (Table 5).

The values of effective liquid diffusivities obtained for the two cases were $2.09 \times 10^{-11}$ and $1.27 \times 10^{-12} \mathrm{~m}^{2} \mathrm{~s}^{-1}$, respectively. The difference between these two values (by an order of magnitude) is most likely due to the difference in thickness of the skin samples which indicate the relatively lack of fundamental nature of the constant effective liquid diffusivity and is described elsewhere (Kar, 2008). The values of effective diffusivity predicted above are in between those predicted by Blank et al. (1984) and Liron et al. (1994) $\left(3.19 \times 10^{-14}\right.$ to $9.57 \times 10^{-14} \mathrm{~m}^{2} \mathrm{~s}^{-1}$ ) and those predicted by Pieper et al. (2003) $\left(3.30 \times 10^{-10} \mathrm{~m}^{2} \mathrm{~s}^{-1}\right)$.

Table 7 - Variation of bottom surface heat transfer coefficient $\left(h_{b}\right)$ based on paper drying experiments.

\begin{tabular}{lcc} 
Drying temperature $\left({ }^{\circ} \mathrm{C}\right)$ & $h_{\mathrm{b}}\left(\mathrm{W} \mathrm{m}^{-2} \mathrm{~K}^{-1}\right)$ & $\begin{array}{r}\text { Standard } \\
\text { deviation }\end{array}$ \\
\hline 25 & 32.32 & 0.050 \\
30 & 33.03 & 0.031 \\
37 & 47.4 & 0.006 \\
\hline
\end{tabular}

3.5. The temporal temperature and spatial average water content profiles predicted using the Fickian liquid diffusion approach - the sensitivity assessment for variable diffusivity cases

Since use of constant liquid diffusivity failed to produce reasonable fits, a temperature and moisture content dependency was introduced for the liquid diffusivity and the optimisation carried out. A series of moisture content and temperature dependency functions have been proposed, which have been summarised by Räderer (2000). Amongst these, the ones below have been used here in general. It was believed that any further modifications or variations of these models would
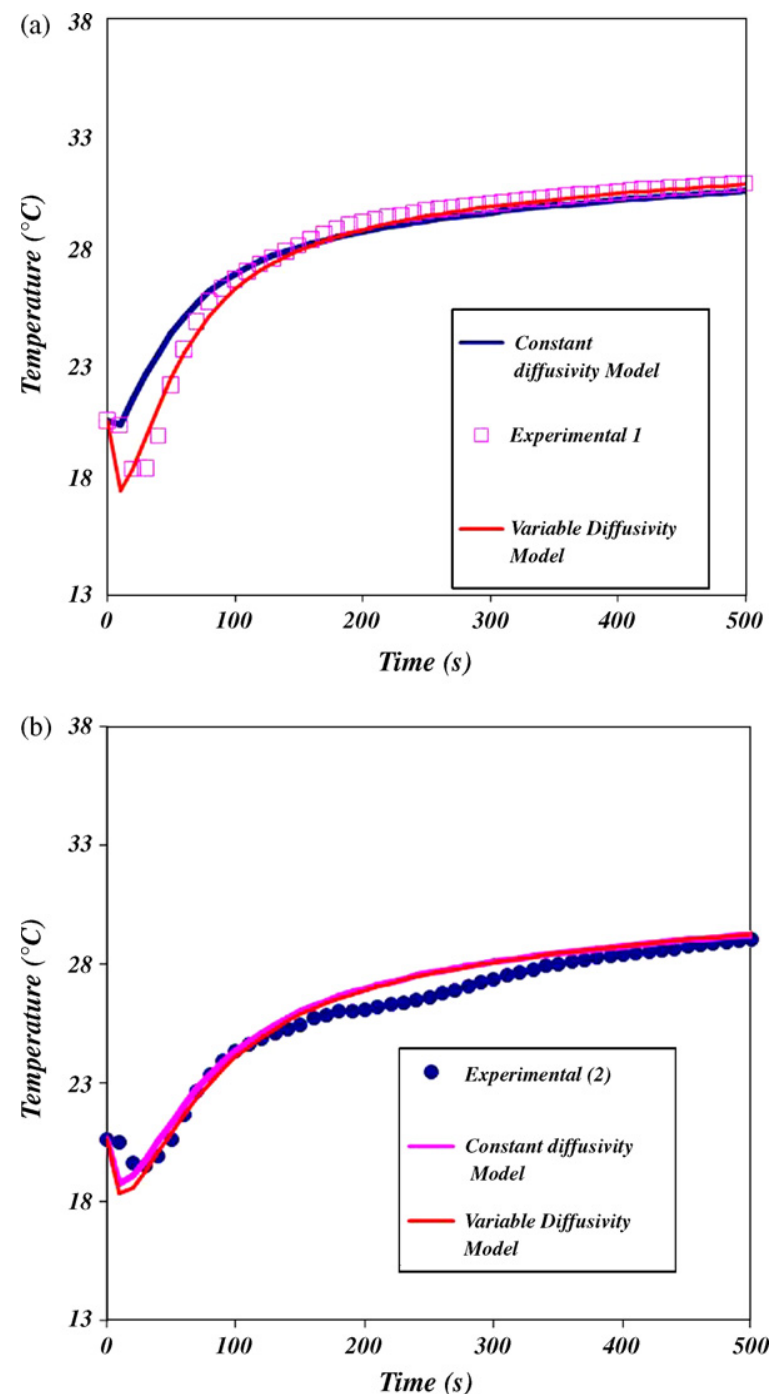

Fig. 13 - Prediction of sample temperature profiles from solution of coupled liquid diffusion and energy equations. (a) Results from experiment 1 and (b) from experiment (2). 
Table 8 - Variables associated with temperature and moisture content and temperature-dependent diffusivity.

\begin{tabular}{lccccc} 
Trial No. & Pre-treatment & Air temperature $\left({ }^{\circ} \mathrm{C}\right)$ & $D_{01}\left(\mathrm{~m}^{2} \mathrm{~s}^{-1}\right)$ & $E_{\mathrm{A}}\left(\mathrm{KJ} \mathrm{mol}^{-1}\right)$ & $\mathrm{z}$ \\
\hline 1 & $25^{\circ} \mathrm{C}$ soak & 37 & $7.53 \times 10^{-12}$ & 40.5 & -0.663 \\
2 & $25^{\circ} \mathrm{C}$ soak & 37 & $9.9 \times 10^{-13}$ & 40.5 & -0.150 \\
\hline
\end{tabular}

not add any new fundamental insights that this paper was intended to address. Here the temperature and moisture content dependency introduced can be mathematically represented as (Räderer, 2000):

$D_{0}=D_{01} e^{-z X}$

where $D_{01}$ is the apparent diffusion coefficient $\left(\mathrm{m}^{2} \mathrm{~s}^{-1}\right)$. The temperature dependency is similar to the Arrhenius equation used in reaction engineering:

$D_{1, \text { eff }}=D_{0} \exp \left(\frac{-E_{A}}{R}\left(\frac{1}{T}-\frac{1}{T_{\infty}}\right)\right)$

$E_{\mathrm{A}}$ represents the activation energy and $R$ the universal gas constant $\left(8.314 \mathrm{~J} \mathrm{~mol}^{-1} \mathrm{~K}^{-1}\right)$. A series of trials were carried out for selecting the appropriate values for activation energy. In an article by Baini and Langrish (2008), it was reported that activation energies for drying of bananas to be in the range of $15.5-20.5 \mathrm{~kJ} \mathrm{~mol}^{-1}$. Lopez et al. (2000) reported acti-
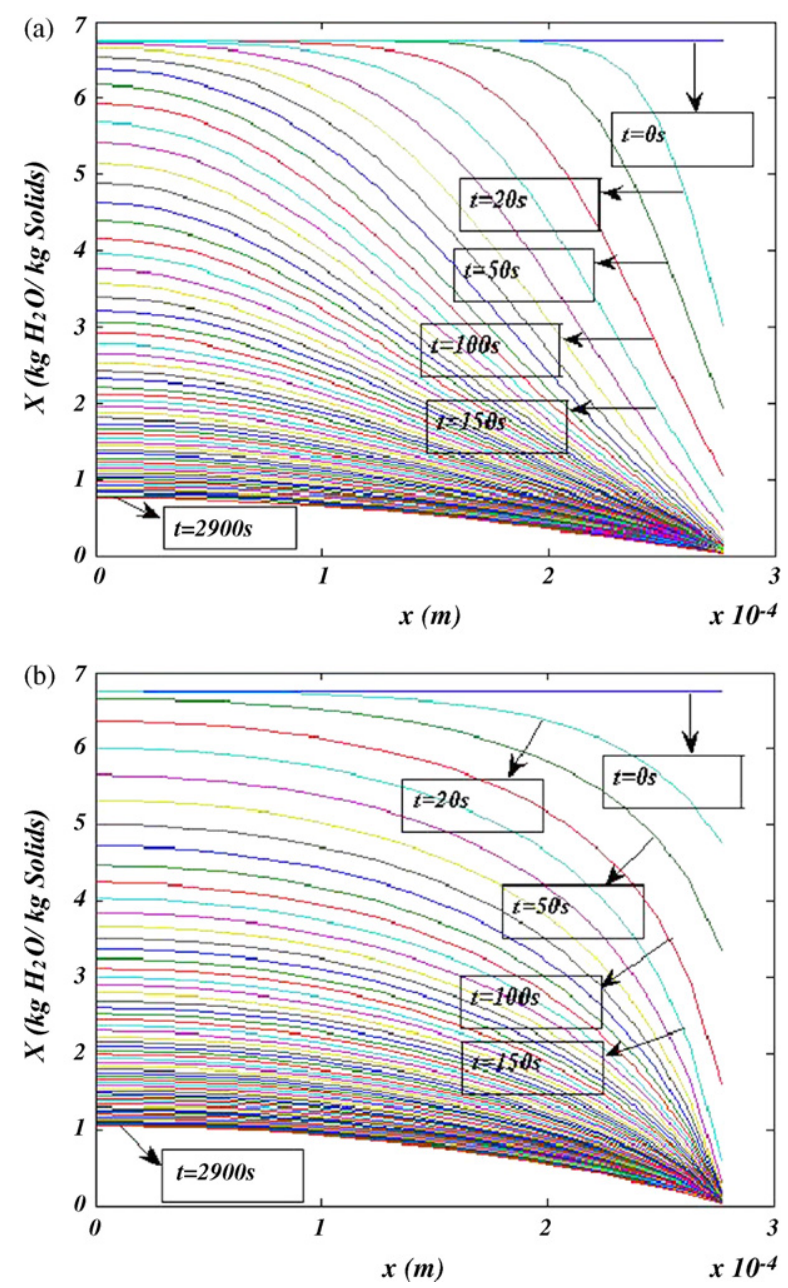

Fig. 14 - Spatial distribution of moisture across skin sample from experiment 1. (a) Constant diffusivity and (b) variable diffusivity.
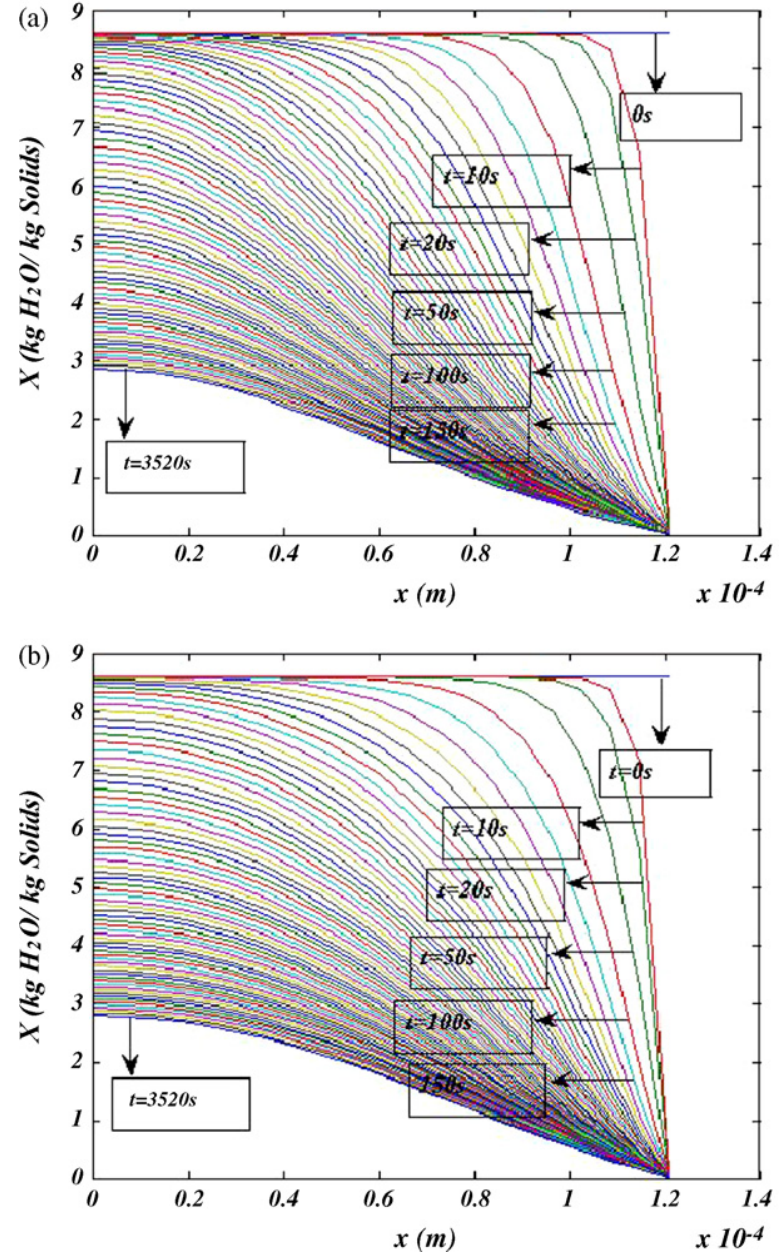

Fig. 15 - Spatial distribution of moisture across skin sample from experiment 2. (a) Constant diffusivity and (b) variable diffusivity.

vation energy values of $19.8 \mathrm{~kJ} \mathrm{~mol}^{-1}$ for thin layer drying of vegetable wastes. In another study, Tong and Lund (1990) estimated the effective moisture diffusivity in various porous food materials in the temperature range between 20 and $100^{\circ} \mathrm{C}$. The activation energy values reported by them were in the range of $50-55 \mathrm{~kJ} \mathrm{~mol}^{-1}$. Furthermore, Dabenedetti (Baini and Langrish, 2008) using molecular dynamics simulations reported that hydrogen bond strengths in pure water were of the order of $20 \mathrm{~kJ} \mathrm{~mol}^{-1}$, while the regular dispersive interactions were of the order of $1 \mathrm{~kJ} \mathrm{~mol}^{-1}$. The covalent bond energies were around $400 \mathrm{~kJ} \mathrm{~mol}^{-1}$. The heat of fusion of ice was $6 \mathrm{~kJ} \mathrm{~mol}^{-1}$ while the heat of vaporization of water was $45 \mathrm{~kJ} \mathrm{~mol}^{-1}$.

Ignoring the covalent bond energy and taking into consideration the activation energies and other energies of interactions mentioned above, a series of optimisation trials were carried out using $E_{\mathrm{A}}$ values in the range from 15.5 to $45 \mathrm{~kJ} \mathrm{~mol}^{-1}$. The most appropriate value for activation energy based on this investigation was actually $40.5 \mathrm{~kJ} \mathrm{~mol}^{-1}$. However, using the activation energy values in this range 
(15-45 $\left.\mathrm{kJ} \mathrm{mol}^{-1}\right)$ did not dramatically alter the fitting accuracies with activation energy values at $40.5 \mathrm{~kJ} \mathrm{~mol}^{-1}$ producing marginally better fits than the others (Kar, 2008).

The fitted moisture content and temperature profiles obtained from the above have also been shown in Figs. 12 and 13(a) and (b) and their corresponding SSE and RMSE values have been tabulated in Table 5 . Table 8 shows the values of $D_{01}, E_{A}$ and $z$, respectively. Overall fits obtained from incorporating the above functional dependencies to the diffusivity are better than those obtained using constant diffusivity.

The fitted moisture content and temperature profiles obtained from the above have also been shown in Figs. 12 and 13(a) and (b) and their corresponding SSE and RMSE values have been tabulated in Table 5 . Table 8 shows the values of $D_{01}, E_{A}$ and $z$, respectively. Overall fits obtained from incorporating the above functional dependencies to the diffusivity are better than those obtained using constant diffusivity. Correspondingly the temperature predictions (refer Fig. 13(a) and (b)) are also very good.

\subsection{Comparison between constant and moisture content/temperature-dependent diffusivity}

As mentioned at the beginning of the introduction, the current study has a background about the effect of moisture transfer on drug delivery. Though all models (after optimisation) find good fits with respect to temperature-time profiles, the constant diffusivity model predicts less accurately the moisture loss trend (refer Fig. 12). The consequence is evident in the spatial distribution of moisture content (Figs. 14 and 15). Figs. 14( $a$ and $b$ ) and 15( $a$ and $b$ ) shows the moisture content distribution for the two skin samples dried at $37^{\circ} \mathrm{C}$. The predictions shown in Figs. 14(a) and 15(a) were obtained using a constant value for effective diffusivity and that in Figs. 15(b) and 16(b) used a moisture content and temperaturedependent diffusivity. They clearly show that the surface water contents are affected by the adoption of model type.

\section{Conclusions}

Based on the study in this work, for thin layer materials (though conclusion could also be generalised to small particles perhaps) it is evident that the drying kinetics models need to have high accuracy to predict the sample temperature profiles correctly. It is important to have a model that accurately predicts the sample moisture content and its spatial distribution. This is because of the fact that skin moisture content plays an important role in permeation of drugs non-invasively through it (Michaels et al., 1975). Since drugs will be applied on the skin surface exposed to the atmosphere, it is very important to ascertain the surface moisture content. This aspect is alarming as it suggests the use of different moisture transport model (though it may model the overall temperature-time and moisture content-time profiles well) can lead to different responses in the surface water contents at different times of dehydration of skin. The surface moisture content is crucial in determining the efficiency of surface treatment such as cosmetics and indeed transdermal drug delivery (hydrophilic drug in particular).

Therefore, a quantitative and fundamentally correct model for moisture transfer is yet to be developed. This is especially true since we have not managed to model the process to allow separately the vapour and liquid transport (Zhang and Datta, 2004; Chen, 2007).

\section{Acknowledgements}

Saptarshi Kar would like to thank Monash Research Graduate School (Monash University) for providing the Monash Graduate Scholarship and the Department of Chemical Engineering (Monash University) for providing the Fee Waiver Scholarship. The experimental instrument was designed and for the most part established by the fourth and the second author of this paper. The help extended by the workshop staff in particular Martin Watkins is also gratefully acknowledged.

\section{Appendix A}

\section{A.1. Calculations}

A closer look at Eqs. (5) and (7) indicates that the density and specific heat of skin samples need to be evaluated. Apart from these, for the Biot number calculations, the thermal conductivity of the skin samples had to be calculated as well. All these properties are a function of both temperature and moisture content. They are evaluated as follows:

$$
\begin{aligned}
& k_{\text {water }}=0.57109+0.0017625 \mathrm{~T}-\left(6.7036 \times 10^{-6}\right) \mathrm{T}^{2} \\
& k_{\text {protein }}=0.17881+0.0011958 \mathrm{~T}-\left(2.7178 \times 10^{-6}\right) \mathrm{T}^{2} \\
& k_{\text {fat }}=0.18071-0.0027604 \mathrm{~T}-\left(1.7749 \times 10^{-7}\right) \mathrm{T}^{2} \\
& \rho_{\text {water }}=997.18+0.0031439 \mathrm{~T}-0.0037574 \mathrm{~T}^{2} \\
& \rho_{\text {protein }}=1329.9-0.5185 \mathrm{~T} \\
& \rho_{\text {fat }}=925.59-0.41757 \mathrm{~T} \\
& c_{\mathrm{p}, \text { water }}=4176.2-0.090864 \mathrm{~T}+0.0054731 \mathrm{~T}^{2} \\
& c_{\mathrm{p}, \text { protein }}=2008.2+1.2089 \mathrm{~T}-0.0013129 \mathrm{~T}^{2} \\
& c_{\mathrm{p}, \text { fat }}=1984.2+1.4733 \mathrm{~T}-0.0048008 \mathrm{~T}^{2}
\end{aligned}
$$

In the above correlations $\mathrm{T}$ indicates the temperature and is in ${ }^{\circ} \mathrm{C}$. The subscripts water, protein and fat denote water, protein and fat, which predominantly make up the chemical composition of skin. The units of thermal conductivity, density and specific heat capacity are $\mathrm{Wm}^{-1} \mathrm{~K}^{-1}, \mathrm{~kg} \mathrm{~m}^{-3}$ and $\mathrm{Jkg}^{-1} \mathrm{~K}^{-1}$, respectively.

Using the correlations above, the solid density of the skin sample ( $\left.\rho_{\text {solids }}\right)$ is calculated as follows (Choi and Okos, 1986):

$\rho_{\text {solids }}=\frac{1}{\left(w_{\text {protein }} / \rho_{\text {protein }}\right)+\left(w_{\text {fat }} / \rho_{\text {fat }}\right)}$

Eq. (A39) indicates that the density, specific heat capacity and thermal conductivities have to be evaluated for the paper samples as well. Since paper is essentially made of fibre, its density, specific heat capacity and thermal conductivity can be calculated as a function of temperature using the following correlations:

$\rho_{\text {fibre }}=1311.5-0.36589 \mathrm{~T}$ 
$c_{\mathrm{p}, \mathrm{fibre}}=1845.9+1.8306 \mathrm{~T}-0.0046509 \mathrm{~T}^{2}$

$k_{\text {fibre }}=0.18331+0.0012497 \mathrm{~T}-\left(3.16 \times 10^{-6}\right) \mathrm{T}^{2}$

$\mathrm{T}$ is the paper sample temperature and is in ${ }^{\circ} \mathrm{C}$. It is assumed that when the skin/paper samples are completely saturated, liquid water occupies all the pore spaces. However, as the samples start to dry, water is lost and replaced by air in these spaces. Hence the physical properties of air also need to be calculated. These were calculated using the following correlations:

$$
\begin{aligned}
k_{\text {air }}= & \left(1.5207 \times 10^{-11}\right) \mathrm{T}^{3}-\left(4.857 \times 10^{-8}\right) \mathrm{T}^{2}+\left(1.0184 \times 10^{-4}\right) \mathrm{T} \\
& -\left(3.933 \times 10^{-4}\right)
\end{aligned}
$$

$$
\begin{aligned}
c_{\mathrm{p}, \text { air }}= & \left(1.9327 \times 10^{-10}\right) \mathrm{T}^{4}-\left(7.999 \times 10^{-7}\right) \mathrm{T}^{3} \\
& +\left(1.1407 \times 10^{-3}\right) \mathrm{T}^{2}-\left(4.4890 \times 10^{-1}\right) \mathrm{T}+\left(1.057 \times 10^{3}\right)
\end{aligned}
$$

$\rho_{\text {air }}=1.2332-0.0033 \mathrm{~T}^{2}$

In the above case $\mathrm{T}$ denotes the temperature and is in Kelvin for estimation of thermal conductivity and specific heat capacity and ${ }^{\circ} \mathrm{C}$ for the estimation of density. All these correlations were adopted from Choi and Okos (1986).

Using the properties for the individual constituents, the overall density, of the skin/paper samples was calculated using the following relations:

$$
\begin{aligned}
\rho_{\text {skin }}= & \left(\rho_{\text {protein }} \times X_{\text {protein }}^{\mathrm{V}}\right)+\left(\rho_{\text {fat }} \times X_{\text {fat }}^{\mathrm{V}}\right)+\left(\rho_{\text {air }} \times \varepsilon\right) \\
& +\left(\rho_{\text {water }} \times X_{\text {water }}^{\mathrm{V}}\right)
\end{aligned}
$$

$\mathrm{X}_{\mathrm{i}}^{\mathrm{V}}$ represents the volume fraction of the individual component (protein, fat and water), $\varepsilon$ is the porosity of the skin sample and is related to the skin moisture content. Details pertaining to the estimation of porosity have been explained elsewhere (Kar, 2008).

The specific heat capacity of the skin sample is calculated as follows:

$c_{\mathrm{p}, \mathrm{sample}}=\sum c_{p, i} w_{i}$

where $w_{i}$ denotes the percentage composition (by weight) of the individual constituents. It can also be termed as the weight fraction.

The calculated thermal conductivity of the skin sample is an average between the thermal conductivity predicted using the parallel model and the series model (Keey, 1972):

$$
\begin{aligned}
& k_{\text {parallel }}=\sum k_{i} X_{i}^{\mathrm{V}} \\
& k_{\text {series }}=\frac{1}{\sum X_{i}^{\mathrm{V}} / k_{i}} \\
& k_{\text {sample }}=\left(\frac{k_{\text {series }}+k_{\text {parallel }}}{2}\right)
\end{aligned}
$$

The percentage composition (by weight) can be estimated from the moisture content $\mathrm{X}$ as follows:

$w_{\text {water }}=\left(\frac{X}{1+X}\right) \times 100$

Michaels et al. (1975) have suggested that at bone dry state, the composition of protein and fat are 67 and $33 \mathrm{wt} \%$, respectively. Based on this information, the percentage composition (by weight) of protein and fat can be calculated as follows:

$w_{\text {protein }}=\left(100-w_{\text {water }}\right) \times 0.67$

$w_{\text {fat }}=\left(100-w_{\text {water }}\right) \times 0.33$

The volume fraction of the individual components can then be calculated from their percentage composition (by weight) as follows:

$X_{i}^{\mathrm{V}}=\frac{w_{i} \times \rho_{\text {skin }}}{\rho_{\mathrm{i}}}$

The volume of the skin sample could be calculated using the following relation:

$\mathrm{V}_{\text {sample }}=\left(\mathrm{A} \times \delta_{\mathrm{dry}}\right)+\left(\frac{\overline{\mathrm{X}} m_{\mathrm{s}}}{\rho_{\mathrm{w}}}\right)$

A is the area of the skin sample and $\delta_{\text {dry }}$ is the thickness of the skin sample at bone dry state. The other terms have already been explained earlier and will not be re-iterated here.

The vapour pressure, vapour density and latent heat of vaporization of water were calculated using the following correlations:

$p^{\text {sat }}(\mathrm{Pa})=\exp \left(23.1964-\frac{3816.44}{\mathrm{~T}+227.02}\right)$

Eq. (A27) is the Antoine's equation, which is commonly used for calculating vapour pressure of most substances. In Eq. (A27), $\mathrm{T}$ denotes the temperature and is in ${ }^{\circ} \mathrm{C}$.

$\lambda_{1}\left(\mathrm{Jkg}^{-1}\right)=\mathrm{A}_{2}\left(\frac{1-\mathrm{T}}{\mathrm{T}_{\mathrm{C}}}\right)^{u}$

In Eq. (A28), $T_{C}$ denotes the absolute critical temperature (Kelvin). For the case of water $A_{2}$ has a value of 52.053 and $u$ a value of 0.321 . The vapour density is calculated using the ideal gas equation (Kar and Chen, 2004).

The thermal conductivity $\left(\mathrm{W} \mathrm{m}^{-1} \mathrm{~K}^{-1}\right)$ of plastic, cardboard and aluminium were estimated from the following correlations (Yaws, 1999):

$k_{\mathrm{al}}=228.210+\left(5.7999 \times 10^{-2}\right) \mathrm{T}-\left(8.6806 \times 10^{-5}\right) \mathrm{T}^{2}$

$k_{\mathrm{cb}} \approx k_{\text {plastic }}=0.18331+0.00124 \mathrm{~T}-\left(3.1683 \times 10^{-6}\right) \mathrm{T}^{2}$

The cardboard and plastic layers were made of the same material (cellulose acetate fibres). $T$ is the temperature and is in Kelvin. The thickness of the aluminium plate is $0.98 \mathrm{~mm}$, the plastic layer has a thickness of $0.28 \mathrm{~mm}$ and the cardboard layer has a thickness of $0.67 \mathrm{~mm}$. The variation of thermal conductivities of plastic, cardboard and aluminium within the temperature range of the drying experiments $\left(18-37^{\circ} \mathrm{C}\right)$ is less than $1 \%$ from their selected values. Hence for all calculations in this paper, the values of $k_{\mathrm{cb}}$ and $k_{\text {plastic }}$ were 
taken as $0.27 \mathrm{~W} \mathrm{~m}^{-1} \mathrm{~K}^{-1}$ and that of aluminium taken as $237 \mathrm{~W} \mathrm{~m}^{-1} \mathrm{~K}^{-1}$, respectively.

The Biot number for skin/paper samples was calculated using the following relationship (Incropera and De Witt, 2000):

$B i=\frac{h_{\mathrm{u}} \delta}{k_{\text {sample }}}$

where $\mathrm{Bi}$ is the Biot number, $\delta(m)$ is the thickness of the skin/paper sample and $k_{\text {sample }}\left(\mathrm{W} \mathrm{m}^{-1} \mathrm{~K}^{-1}\right)$ is the thermal conductivity of the skin/paper sample.

The total solids concentration $\left(c_{\mathrm{s}}\right)$ used in the liquid diffusion equation (Eq. (9)), is calculated using the mathematical expression shown in Eq. (10). Mathematically, the solids concentration is calculated as follows:

$c_{\mathrm{s}}=\frac{m_{\mathrm{s}}}{\mathrm{V}_{\text {solids }}+\mathrm{V}_{\text {water }}+\mathrm{V}_{\text {air }}}$

where $V_{\text {solids }}\left(\mathrm{m}^{3}\right), \mathrm{V}_{\text {water }}\left(\mathrm{m}^{3}\right), \mathrm{V}_{\text {air }}\left(\mathrm{m}^{3}\right)$ are the volumes of solids, moisture and air making up the skin sample at any given instance during the drying process. The volume of air can be re-written in terms of sample porosity $(\varepsilon)$ as follows:

$\mathrm{V}_{\mathrm{air}}=\mathrm{V}_{\text {sample }} \varepsilon$

Furthermore, the volume of water $\left(\mathrm{V}_{\text {water }}\right)$ can be re-written in terms of the moisture content $(\mathrm{X})$ as follows:

$\mathrm{V}_{\text {water }}=\frac{X m_{\mathrm{s}}}{\rho_{\text {solids }}}$

Substituting Eq. (A33) and Eq. (A34) into Eq. (A32), the total solids concentration $\left(c_{\mathrm{s}}\right)$ can be written as

$$
c_{\mathrm{s}}=\frac{1-\varepsilon}{\left(1 / \rho_{\mathrm{solids}}\right)+\left(\mathrm{X} / \rho_{\mathrm{W}}\right)}
$$

\section{A.2. Optimisation technique}

The optimisation technique employed extensively in this paper is knows as the downhill simplex method developed by Nedler and Mead (1965). It is a numerical method for minimising an objective function in a multi-dimensional space. The method uses the concept of a simplex, which is a polytope of $N+1$ vertices in $N$ dimensions (a line segment in a line, a triangle in a plane and a tetrahedron in a three-dimensional space). The method approximately finds a local optimal solution to a problem with $\mathrm{N}$ variables when the objective function varies smoothly. The algorithm generates a new test position by extrapolating the behaviour of the objective function measured at each test point arranged as a simplex. The algorithm then chooses to replace one of these test points with a new test point such that the algorithm can progress. One of the simple methods used to ensure the continuity of the algorithm is to replace the worst point in the initial simplex by a point reflected from the centroid of the simplex formed by the remaining points. If this latest point is better than the best current point, a whole new simplex is formed from the latest point by a process of exponential stretching. On the contrary if the latest point is not much better than the current best point, the simplex is shrunk. This procedure can be implemented in MATLAB (Mathworks Inc., USA, 2006) using the 'fminsearch' function. The objective functions used in this paper are the difference between the experimental and predicted water con- tent profiles or the predicted and experimental temperature profiles as shown below:

$F 1=\left|X_{\text {exp }}-X\right|$
$F 2=\left|T_{\text {exp }}-T\right|$

The overall function of this algorithm is to minimise the values of $F 1$ and $F_{2}$.

\section{A.3. Validation of the bottom surface heat transfer coefficient $\left(h_{b}\right)$ based on the paper drying experiments}

The bottom surface heat transfer coefficient $\left(h_{b}\right)$ was evaluated using the optimisation algorithm based on the temperature trends from the skin drying experiments. The upper surface heat transfer coefficient $\left(h_{u}\right)$, which is used in the optimisation algorithm is obtained from the paper drying experiments as described in Section 2.4. It may therefore be argued that the use of $h_{\mathrm{u}}$ evaluated from the paper drying experiments may not necessarily be the same as that for skin drying. It was therefore decided to obtain $h_{\mathrm{b}}$ values based on the experimental trends generated from paper drying. Since the moisture content profile for paper drying experiments followed a linear trend, mathematically at any instance during drying the average moisture content can be represented as follows:

$\bar{X}=B_{1} t+C_{1}$

The energy balance for the paper samples undergoing drying is similar to Eq. (7) and is as follows:

$\rho_{\text {paper }} c_{\text {p,paper }} V_{\text {paper }} \frac{d T}{d t}=h_{u} A\left(T_{\infty}-T\right)+\dot{E}_{\mathrm{V}} \lambda_{l}+U A\left(T_{\infty}-T\right)$

$\rho_{\text {paper, }} \rho_{\text {p,paper }}$ and $V_{\text {paper }}$ denotes the density, specific heat capacity and volume of the paper samples, respectively. Sample calculation of these properties has been in Appendix A.1.

The vapour flux due to evaporation is represented as follows:

$\dot{E}_{\mathrm{v}}=-m_{\mathrm{s}} B_{1}$

The overall heat transfer coefficient $(U)$ is the same as in Eq. (6). The solution of Eq. (A39) predicts the temperature-time profile for the paper samples as they dry. This is fitted against the experimental temperature trends to get the value of the bottom surface heat transfer coefficient $\left(h_{b}\right)$. The bottom surface heat transfer coefficient $\left(h_{b}\right)$ obtained using this approach were compared with those calculated with reference to the skin drying experimental results. Fig. 16 shows the variation of the bottom surface heat transfer coefficient with respect to drying temperature based on the paper drying experiments. Table 7 shows the values.

Fig. 16 clearly shows that the bottom surface heat transfer coefficient $\left(h_{\mathrm{b}}\right)$ obtained from the paper drying experiments for drying at $37^{\circ} \mathrm{C}\left(47.4 \mathrm{~W} \mathrm{~m}^{-1} \mathrm{~K}^{-1}\right)$ is similar to those obtained from the skin drying experiments (refer Table 6). This clearly indicates that both the heat transfer coefficients (upper and bottom surface) are dependent on the thermophysical properties of fluid (dry air) flowing along the surface of the plate 


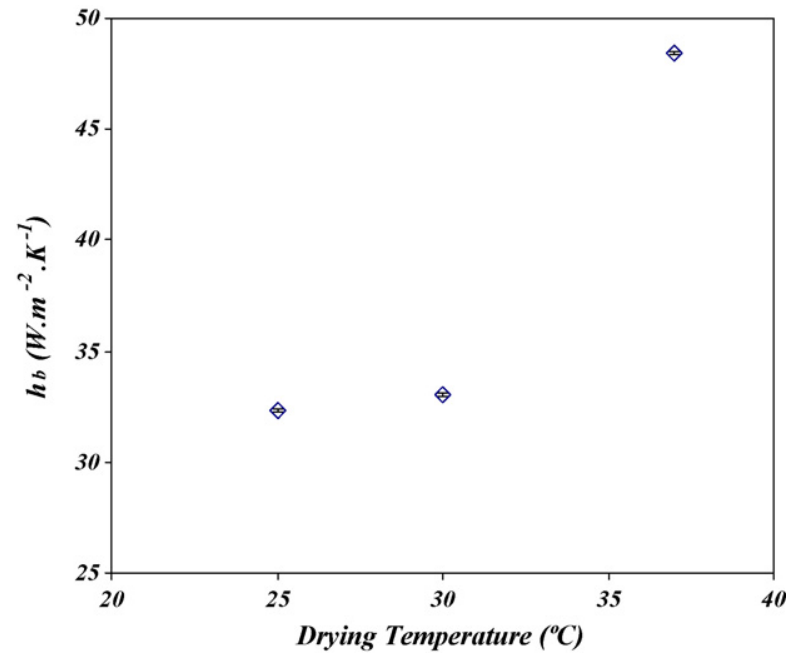

Fig. 16 - Variation of bottom face heat transfer coefficient $\left(h_{b}\right)$ with respect to drying temperature from paper drying experiments (mean \pm S.D.).

and the geometry of the system and independent of the drying material. The correlations for convective heat and mass transfer for flow of fluid along a flat plate (Eq. (2)) does not hold good in this case mainly due to the geometry of the system (the sample plate as shown in Fig. 2(a) and (b)).

Eq. (A39) holds good if the effect of internal conduction within the paper sample is negligible. The thickness of paper samples dried was in the range from 120 to $125 \mu \mathrm{m}$. Since paper is essentially made of fibre, its thermal conductivity at $37^{\circ} \mathrm{C}$ was estimated to be about $0.065 \mathrm{~W} \mathrm{~m}^{-1} \mathrm{~K}^{-1}$. The upper surface heat transfer coefficient as determined experimentally in Section 2.4 at $37^{\circ} \mathrm{C}$ was found to have a value of $42.64 \mathrm{~W} \mathrm{~m}^{-2} \mathrm{~K}^{-1}$. Based on these parameters, the Biot number was estimated to be 0.08 , which again is far below the critical limit (Chen and Peng, 2005).

It may also be argued that at a constant evaporation temperature, the following simple heat balance equation is sufficient to provide a reasonable value for the bottom surface heat transfer coefficient $\left(h_{b}\right)$ (Chen et al., 2002):

$h_{\mathrm{u}}\left(T_{\infty}-\mathrm{T}\right)+\mathrm{U}\left(\mathrm{T}_{\infty}-\mathrm{T}\right)=h_{\mathrm{m}}\left(\rho_{\mathrm{v}, \mathrm{s}}-\rho_{\mathrm{v}, \infty}\right) \lambda_{1}$

Eq. (A41) does not take into account the sensible heat term. The bottom surface heat transfer coefficient $\left(h_{b}\right)$ predicted using this approach were much higher (around $80-150 \mathrm{~W} \mathrm{~m}^{-2} \mathrm{~K}^{-1}$ ) than those obtained by optimising the solution of Eq. (A39) (around 30-45 $\mathrm{W} \mathrm{m}^{-2} \mathrm{~K}^{-1}$ ). Furthermore, if the bottom surface heat transfer coefficient obtained using Eq. (A41) is used directly in Eq. (A39) along with $h_{u}$, the predicted temperature profiles become very poor (results not shown).

It is envisaged that the above equation only holds good when the sample temperature is equal to the theoretical wetbulb temperature. However, in the paper drying experiments, the time period for which the sample temperature was at its theoretical wet bulb value was very short. The saturation temperature, which remained unchanged for most of the drying period, was above the wet bulb temperature. Therefore, the sensible heat term (LHS of Eq. (A39)) is very critical in determining the bottom surface heat transfer coefficient accurately.

\section{References}

Adhikari, B.P., Howes, T., Bhandari, B.R., Yamamoto, S. and Truong, V., 2002, Application of a simplified method based on regular regime approach to determine the effective moisture diffusivity of mixture of low molecular weight sugars and maltodextrin during desorption. J. Food Eng., 54: 157-165.

Akpinar, E.K. and Bicer, Y., 2005, Modelling of the drying of eggplants in thin-layers. Int. J. Food Sci. Technol., 40: 273-281.

Ashworth, J.C. and Keey, R.B., 1972, The evaporation of moisture from wet surfaces. Chem. Eng. Sci., 27: 1797-1806.

Baini, R. and Langrish, T., 2008, An assessment of the mechanisms for diffusion in the drying of bananas. J. Food Eng., 85: 201-214.

Blank, I.H., Moloney, J., Emslie, A.G., Simon, I. and Apt, C., 1984, The diffusion of water across the stratum corneum as a function of its water content. J. Invest. Dermatol., 82: 188-195.

Chen, X.D., 2007, Simultaneous heat and mass transfer in drying of food materials, in Handbook of Food and Bioprocess Modelling Techniques, Sablani, S.S., Rahman, M.S., Datta, A.K., \& Mujumdar, A.S. (eds) (CRC Press, Boca Raton, Florida, USA), pp. 179-234.

Chen, X.D. and Peng, X.F., 2005, Modified Biot number in the context of air-drying of small moist porous objects. Drying Technol., 23(1): 83-103.

Chen, X.D., Lin, S.X.Q. and Chen, G., 2002, On the ratio of heat to mass transfer coefficient for water evaporation and its impact upon drying modelling. Int. J. Heat Mass Transfer, 45: 4369-4372.

Choi, Y. and Okos, M.R., 1986, Effects of temperature and composition on the thermal properties of foods, in Food Engineering and Process Applications, Vol. 1. Transport Phenomena, Le Maguer, M. and Jelen, P., Jelen, P. (eds) (Elsevier, London, UK), pp. 93-101.

Coumans, W.J., 1987, Power law diffusion in drying processes, $\mathrm{PhD}$ Thesis, Technical University of Eindhoven, Netherlands.

Crank, J., (1976). The Mathematics of Diffusion (2nd ed.). (Clarendon Press, Oxford, UK).

Datta, A.K., 2007, Porous media approaches to studying simultaneous heat and mass transfer in food processes I. Problem formulations. J. Food Eng., 80(1): 80-95.

Doymaz, I., 2005, Drying behaviour of green beans. J. Food Eng., 69: 161-165.

Gay, C.L., Guy, R.H., Golden, G.H., Mak, V.H.W. and Francoeur, M.L., 1994, Characterization of low-temperature (i.e., $<65^{\circ} \mathrm{C}$ ) lipid transitions in human stratum corneum. J. Invest. Dermatol., 103(2): 233-239.

Golden, G.M., Guzek, D.B., Harris, R.R., Mc Kie, J.E. and Potts, R.O., 1986, Lipid thermotropic transitions in human stratum corneum. J. Invest. Dermatol., 86(3): 255-259.

Incropera, F.P. and De Witt, D.P., (2000). Fundamentals of Heat and Mass Transfer. (John Wiley and Sons (Asia) Pte Ltd, Singapore).

Kar, S., 2008, The phenomena of moisture transport across porcine skin-experimental and theoretical investigations, $\mathrm{PhD}$ Thesis, Department of Chemical Engineering, Monash University, Clayton, Victoria, Australia.

Kar, S. and Chen, X.D., 2004, Effect of high mass fluxes on heat and mass transfer through a flat surface. Trans IMechE (Part E), 218: 213-220.

Kasting, G.B., Barai, N.D., Wang, T.-F. and Nitsche, J.M., 2003, Mobility of water in human stratum corneum. J. Pharm. Sci., 92(11): 2326-2340.

Keey, R.B., (1972). Drying of Loose and Particulate materials. (Hemisphere Publishing Corporation, London, UK).

Lagarias, J.C., Reeds, J.A., Wright, J.A., Wright, M.H. and Wright, P.E., 1988, Convergence properties of the Nedler-Mead simplex method in low dimensions. SIAM J. Optimiz., 9(1): 112-147.

Lin, S.-Y., Duan, K.-J. and Lin, T.-C., 1996, Simultaneous determination of the protein conversion process in porcine stratum corneum after pre-treatment with skin enhancers by a combined microscopic FT-IR/DSC system. Spectrochimica Acta (Part A), 52: 1671-1678. 
Liron, Z., Clewell, H.J. and Mc Dougal, J.N., 1994, Kinetics of water vapour sorption in porcine stratum corneum. J. Pharm. Sci., 83(5): 692-698.

Lopez, A., Iguaz, A., Esnoz, A. and Virseda, P., 2000, Thin-layer drying behaviour of vegetable wastes from wholesale market. Drying Technol., 18(4): 995-1006.

Michaels, A.S., Chandrasekaran, S.K. and Shaw, J.E., 1975, Drug permeation through human skin: theory and in-vitro experimental measurement. AIChE J., 21(5): 985-996.

Nedler, J.A. and Mead, R., 1965, A simplex method for function minimization. Comput. J., 7: 308-313.

Page, G., 1949, Factors influencing the maximum rates of air drying shelled corn in thin layers, M.S Thesis, Purdue University, West Lafayette, Indiana, USA.

Pakowski, Z. and Mujumdar, A.S., 2006, Basic process calculations and simulations in drying, in Handbook of Industrial Drying, Mujumdar, A.S. (ed). (CRC Press, Boca Raton, Florida, USA)

Pakowski, Z., Glebowski, M. and Adamski, R., 2006, Modeling of drying of highly shrinking materials using hydrogels as an example. Drying Technol., 24: 1075-1081.

Pezzutti, A. and Crapiste, G.H., 1997, Sorptional equilibrium and drying characteristics of garlic. J. Food Eng., 31: 113-123.

Pieper, J., Charalambopoulou, G., Steriotis, G., Vasenkov, S., Desmedt, S. and Lechner, R.E., 2003, Water diffusion across fully hydrated porcine stratum corneum. Chem. Phys. (B), 292 465-476.

Potts, R.O. and Francoeur, M.L., 1991, The influence of stratum corneum morphology on water permeability. J. Invest. Dermatol., 96: 495-499.

Räderer, M., 2000, Drying of viscous, shrinking products: modelling and experimental validation, PhD Thesis, Technical University of Munich, Germany.
Rahman, M.S., (2000). Food Properties Handbook. (CRC Press, USA). Scheuplein, R.J., 1965, Mechanism of percutaneous absorption. I. Routes of penetration and the influence of solubility. J. Invest. Dermatol., 45: 334-340.

Schoeber, W., 1976, Regular Regimes in sorption processes, $\mathrm{PhD}$ Thesis, Technical University of Eindhoven, Netherlands.

Simal, S., Rosselló, C., Berna, A. and Mulet, A., 1998, Drying of shrinking cylinder-shaped bodies. J. Food Eng., 37: 423-435.

Stanish, M.A., Schajer, G.S. and Kayrhan, F., 1986, A mathematical model of drying for hygroscopic porous media. AIChE J., 32(8): 1301-1311.

Stockdale, M., 1978, Water diffusion coefficients versus water activity in stratum corneum: a correlation and its implications. J. Soc. Cosmet. Chem., 29: 625-639.

Sutar, P.P. and Prasad, R., 2007, Modelling microwave vacuum drying kinetics and moisture diffusivity carrot slices. Drying Technol., 25: 1695-1702.

Tanojo, H., Bouwstra, J.A., Junginger, H.E. and Boddé, H.E., 1997, In vitro human skin barrier modulation by fatty acids: skin permeation and thermal analysis studies. Pharm. Res., 14(1): 42-49.

Tong, C.H. and Lund, D.B., 1990, Effective moisture diffusivity in porous materials as a function of temperature and moisture content. Biotechnol. Progr., 6: 67-75.

Treybal, R.E., (1980). Mass-Transfer Operations (3rd ed.). (McGraw Hill, Singapore).

Vijayraj, B., Saravanan, R. and Renganarayanan, S., 2007, Studies on thin layer drying of bagasse. Int. J. Energy Res., 31: 422-437.

Yaws, C.L., (1999). Chemical Properties Handbook. (McGraw Hill, New York, USA).

Zhang, J. and Datta, A.K., 2004, Some considerations in modeling of moisture transport in heating of hygroscopic materials. Drying Technol., 22(8): 1983-2008. 